\title{
Impact of Synthetic Arctic Argo-Type Floats in a Coupled Ocean-Sea Ice State Estimation Framework
}

\author{
An T. Nguyen, Patrick Heimbach, ${ }^{\text {a }}$ Vikram V. Garg, and Victor Ocaña \\ The University of Texas at Austin, Austin, Texas \\ CRAIG LEE AND LuC RAINVILLE \\ University of Washington, Seattle, Washington
}

(Manuscript received 18 September 2019, in final form 4 June 2020)

\begin{abstract}
The lack of continuous spatial and temporal sampling of hydrographic measurements in large parts of the Arctic Ocean remains a major obstacle for quantifying mean state and variability of the Arctic Ocean circulation. This shortcoming motivates an assessment of the utility of Argo-type floats, the challenges of deploying such floats due to the presence of sea ice, and the implications of extended times of no surfacing on hydrographic inferences. Within the framework of an Arctic coupled ocean-sea ice state estimate that is constrained to available satellite and in situ observations, we establish metrics for quantifying the usefulness of such floats. The likelihood of float surfacing strongly correlates with the annual sea ice minimum cover. Within the float lifetime of 4-5 years, surfacing frequency ranges from 10-100 days in seasonally sea icecovered regions to 1-3 years in multiyear sea ice-covered regions. The longer the float drifts under ice without surfacing, the larger the uncertainty in its position, which translates into larger uncertainties in hydrographic measurements. Below the mixed layer, especially in the western Arctic, normalized errors remain below 1, suggesting that measurements along a path whose only known positions are the beginning and end points can help constrain numerical models and reduce hydrographic uncertainties. The error assessment presented is a first step in the development of quantitative methods for guiding the design of observing networks. These results can and should be used to inform a float network design with suggested locations of float deployment and associated expected hydrographic uncertainties.
\end{abstract}

\section{Introduction}

\section{a. The Arctic Ocean subsurface observations}

The large-scale Arctic Ocean circulation comprises a near-surface anticyclonic wind-driven gyre in the Canada Basin, the Beaufort Gyre, which is bounded to the east by the Transpolar Drift current system, and a cyclonic boundary current at depth (Rudels 2012). Hydrographic measurements at depth reveal warm and saline Atlantic Water (AW) entering the Eurasian Basin through Fram Strait and modified AW through the Saint Anna Trough (Fig. 1a), then flowing anticlockwise

\footnotetext{
${ }^{\text {a }}$ Current affiliation: Oden Institute for Computational Engineering and Sciences, Institute for Geophysics, Jackson School of Geosciences, The University of Texas at Austin, Austin, Texas.
}

Corresponding author: An T. Nguyen, atnguyen@oden.utexas.edu following topographically steered paths eastward into the Canada Basin, and eventually exiting the Arctic at depth through Fram Strait (Schauer and Fahrbach 2004; Rudels 2012, 2015).

Albeit sparsely sampled, there is observational evidence for an increase, over the last two decades, in pulses of warm AW entering the Arctic and reaching the eastern extent of the Eurasian Basin (Dmitrenko et al. 2010; Polyakov et al. 2012, 2017). These changes have been accompanied by a decline in sea ice extent as observed from satellite remote sensing (Kwok and Cunningham 2015; Kwok 2018). They raise questions regarding the potential for enhanced interaction between the incoming warm AW and the near-surface mixed layer (Polyakov et al. 2017) and its impact on enhanced sea ice melt from below. The ability to adequately observe $\mathrm{AW}$ and water mass transformation along its path is crucial to improve understanding of the origins of Arctic system changes and the representation 

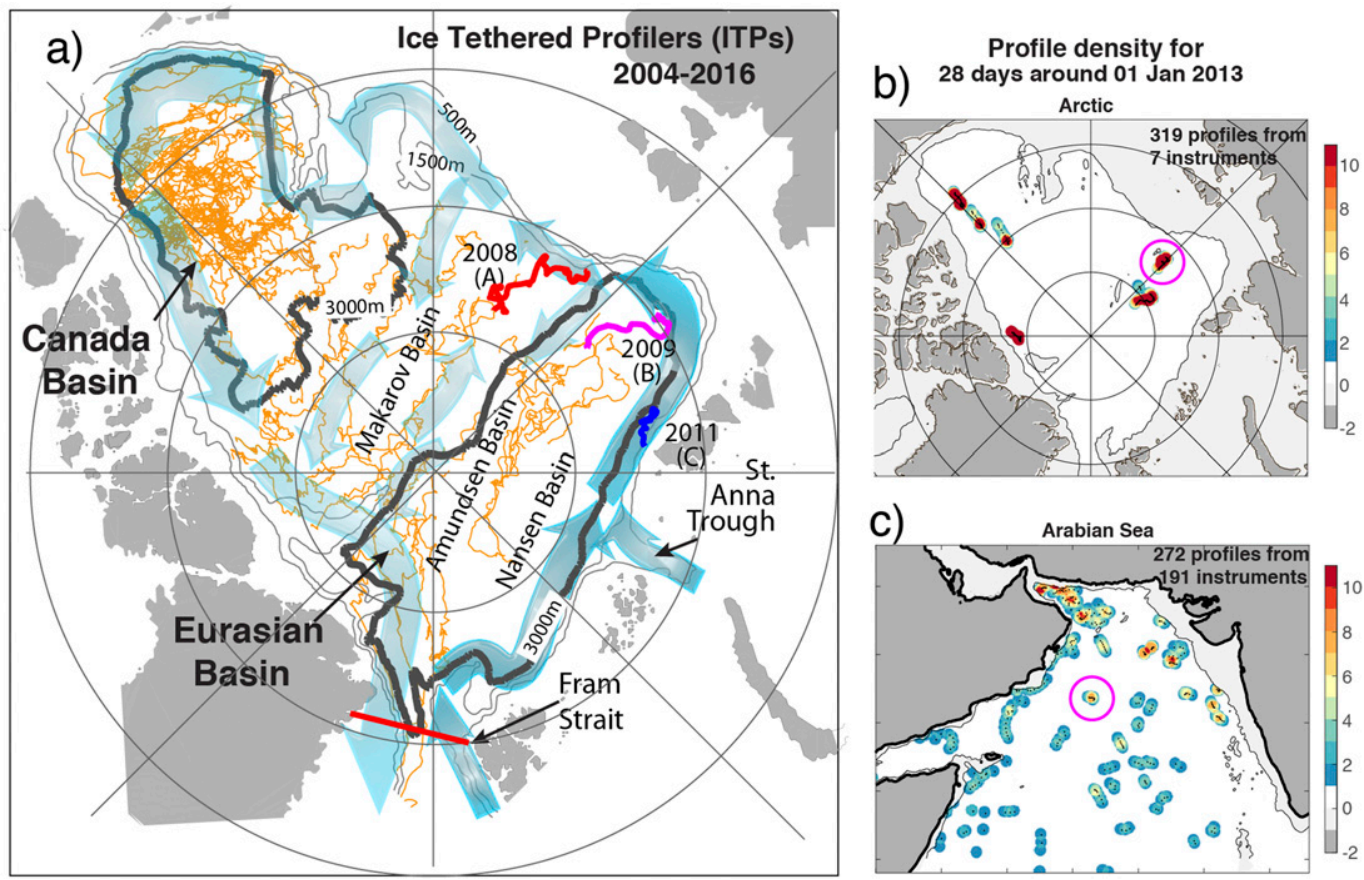

FIG. 1. (a) Schematic pathway of the subsurface Atlantic Water (cyan arrows) with overlaid ITP trajectories (2004-16, orange), revealing the contrast in ITP spatial coverage between the Eurasian and Canada Basins. The AW pathway is inferred from sparse hydrographic measurements by Rudels (2012), with the incoming branch shown in dark cyan and recirculation in light cyan (Rudels 2012; Pnyushkov et al. 2013). Three ITP trajectories are highlighted for the years 2008 (A, red), 2009 (B, magenta), and 2011 (C, blue). Distribution of profiles within a 28-day period around January 2013 are compared between (b) ITP in the Arctic and (c) Argo in the Arabian Sea. The color scales in (b) and (c) provide an indication of data density. During this period, even though similar numbers of profiles are found in both regions, the spatial distribution of data coverage is very different. In the Arabian Sea, data are distributed closer to the Argo-targeted spacing of one measurement every $3^{\circ} \times 3^{\circ}$ (magenta circle). In the Arctic, ITP data, though sampled at very high temporal resolution, are significantly more clustered in space, as indicated by the high density.

of hydrographic properties in Arctic Ocean-sea ice models used for reconstruction and prediction.

Obtaining hydrographic observations of adequate spatial and temporal coverage for ocean climate diagnostics in the Arctic, in particular to perform basinwide budgets of heat and freshwater, is difficult due to the presence of sea ice and the harsh environment, particularly in winter. Sampling of the Arctic-wide state has thus traditionally been sparse and seasonally biased, which has adversely impacted the development of a representative hydrographic climatology and quantitative estimates of interannual variability. The deployment of ice-tethered profilers (ITPs) beginning in 2004 (Fig. 1a; Toole et al. 2006, 2011; Krishfield et al. 2008) has greatly increased the number of hydrographic observations in the upper $800 \mathrm{~m}$ in the central western Arctic, and has helped improve our understanding of Arctic hydrographic properties (Timmermans et al. 2011, 2012, 2018) and mixing (Timmermans et al. 2008; Toole et al. 2010; Cole et al. 2014; Nguyen et al. 2017).
The spatial distribution of ITP-based measurements is restricted by the need to mount the profilers on ice floes and by their drift along with the ice motion (Fig. 1a). The constraint that ITPs follow sea ice motion poses a challenge for sampling the AW along its pathway. North of Fram Strait, at the AW entrance into the Arctic, seasonal sea ice is in contact with the warm AW and ice motion is predominantly southward (Kwok et al. 2004; Beszczynska-Möller et al. 2012), making the region nonoptimal for ITP deployment. Farther downstream in the Eurasian Basin, the general sea ice motion is along the Transpolar Drift and promotes advection of profilers away from the AW boundary current (ITP tracks A-C in Fig. 1a). The dependence of ITP measurements on the presence of sea ice and its drift can also pose a challenge in situations where up- and downstream information is required to establish causal relations, since the sea ice presence and drift need not follow the flow we are interested in. For instance, ITP tracks A-C in Fig. 1a happened in the wrong chronological order, with the track farthest downstream being the earliest. 


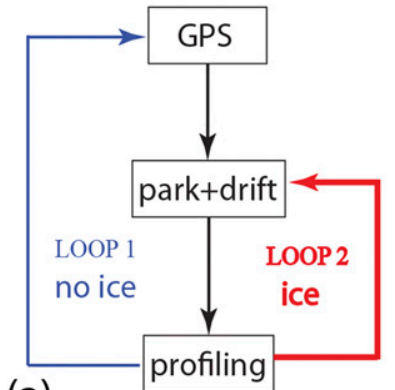

(a)

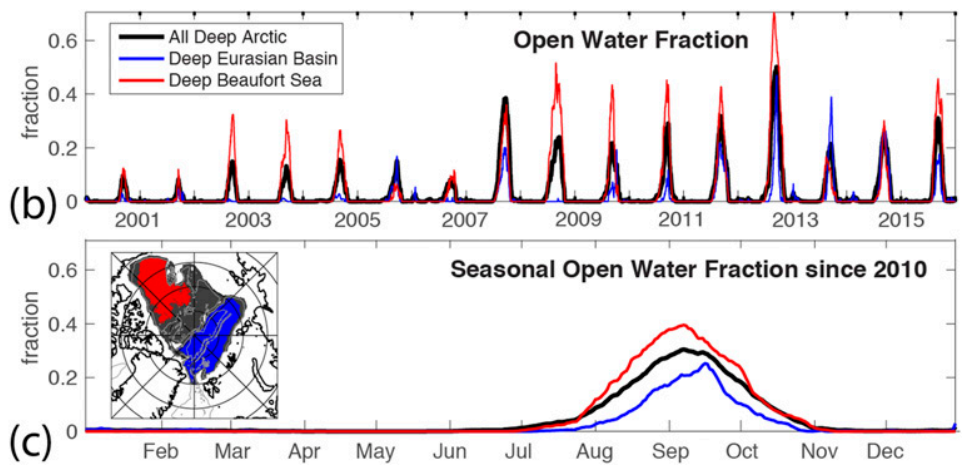

FIG. 2. (a) Flowchart of the two modes in which an Argo float is thought to operate in the Arctic. Loop 1 corresponds to open-water conditions. In the presence of sea ice, the float operates in Loop 2 without surfacing to communicate with the satellite and relay data. In the seasonal ice zone, the float could potentially remain in Loop 2 mode through the winter months. (b) Time series of open-water fraction in the deep Arctic Basin (regions with depth $>3000 \mathrm{~m}$ ) from SSM/I data showing an increase in the mean, beginning in 2008. (c) Open-water fraction (2010-15 mean) showing ice-free conditions (when floats can surface) in up to $40 \%$ of the deep Arctic Basin during summer months.

The small number of ITPs operating concurrently within any given time window poses an additional challenge for separating temporal and spatial variability at the basin scale. To illustrate the underlying issue, we compare the ITP spatial sampling pattern in the Arctic (Fig. 1b) with the sampling pattern of Argo floats in a representative region of the World Ocean, the Arabian Sea (Fig. 1c) during winter 2013. Although the total number of profiles in these two regions is similar, their spatial and temporal coverage is completely different. Argo floats are distributed more or less evenly in the Arabian Sea, providing geographically distributed coverage similar to the Argo target (one float in each $3^{\circ} \times$ $3^{\circ}$ box; Gould et al. 2004). ITP profiles, although providing great temporal resolution and along-track spacing, are clustered around a handful of tracks, for example, 2-6 profiles per day, at separation distance of less than a few kilometers (Toole et al. 2011; Zhao et al. 2016; Fig. 1b). Their high temporal resolution, combined with their relative drift compared to the underlying ocean also leads to high spatial resolution locally, but cannot achieve largescale to basinwide observational sampling.

In regions where ITP coverage is sparse, multiyear mooring measurements such as those at Fram Strait and from the Nansen and Amundsen Basins Observational System (NABOS) project have provided invaluable constraints and improved understanding of the time mean and variable circulation in the highly dynamic eastern Arctic (Pnyushkov et al. 2013; Polyakov et al. 2017; Pnyushkov et al. 2018). With the decreasing ice thickness (Kwok and Cunningham 2015; Kwok 2018) and more open-water fraction in the Arctic (Serreze and Meier 2019; Fig. 2b), as well as an increase in ice breakers capable of crossing thick ice in the central
Arctic and commercial ships through newly open shipping routes (Melia et al. 2016), there is a potential increased opportunity for deployment of Argo floats in the Arctic. To expand sustained observational capabilities of the Arctic water column beyond fixed-mooring arrays, this work examines the value that Argo-type observations may add to sampling the deep Arctic Mediterranean that is mostly invisible to the current ITP observing network.

\section{b. Argo-type floats in the Arctic}

To meet the challenges of measuring ocean properties under Arctic conditions, we explore Argo-type floats as an addition to the ITP network. The sampling strategy would involve having the floats drift along with the ocean circulation at a particular parking depth, for example, the depth of the core AW layer, offering the possibility of efficiently sampling water masses along their pathways.

Since its first deployment in 1999, the array of Argo profiling floats has revolutionized the way the ocean is observed, with close to 4000 active floats currently sampling the upper $2000 \mathrm{~m}$ of the ocean equatorward of $60^{\circ}$ latitude, and relaying data in near-real time (Roemmich et al. 2009; Riser et al. 2016; and references therein). With the recent technological advances in float design, successful deployments of Argo-type instruments under seasonal sea ice (Wong and Riser 2011, 2013; Riser et al. 2018) and in shallow regions (Purokoski et al. 2013; Westerlund and Tuomi 2016) have been demonstrated. This opens the possibility of subsurface hydrography data acquisition at spatial and temporal coverage comparable to that in lower latitudes.

Adopting the Argo float prototype and infrastructure for the Arctic has several crucial advantages, including 
low cost, ease of deployment, standardized procedures for timely data processing and dissemination, and international support. The floats are relatively inexpensive and incorporate the most advanced instrumentation available. As long as there is open water, they can be easily deployed by untrained personnel with no special skills, and no special equipment is required [they are lowered very gently on a rope, into the water from a vessel that has slowed to a speed of $1 \mathrm{kt}$ or $0.5 \mathrm{~m} \mathrm{~s}^{-1}$ ]. There is an existing framework for assembling, processing, and disseminating data at Argo data centers (ADC). All of these factors suggest that a float-based observing system can be scaled to provide a well distributed spatial and temporal coverage of the Arctic interior that targets water masses not accessible by ITPs or gliders.

\section{c. The need for uncertainty quantification}

A major challenge to the deployment of Argo-type floats in the Arctic has been the presence of sea ice, which inhibits the floats' ability to surface, determine their position and relay data to the satellites, thus limiting their effective usage in ice-covered regions (Fig. 2; Klatt et al. 2007; Riser et al. 2016). As depicted in Fig. 2, for an Argo float in the Arctic, geolocation and transmission of data will be limited to seasonally ice-free areas and leads/cracks in sea ice in the Arctic interior. During winter months, when the Arctic is $100 \%$ covered by sea ice, floats may continue to drift at their parking depth and take subsurface profile measurements, but the location where these measurements are taken is not known. Uncertainty over the float's position increases with nonsurfacing (silent) time and translates into uncertainty in the inferred geolocated hydrography (Chamberlain et al. 2018).

Even if the floats cannot surface regularly during winter months, it is reasonable to expect that collecting subsurface hydrographic data will nonetheless be very useful (Chamberlain et al. 2018). However, a quantitative assessment of the importance and usefulness of such measurements requires understanding of how uncertainty over the float's position accumulates with silent time, how this uncertainty maps onto uncertainty in the inferred, geolocated hydrography, and whether the data collected provide value despite the elevated uncertainty. The focus of this paper is simulation-based quantification of expected uncertainty and the assessment of the usefulness of hydrographic measurements from Argo-type floats in the Arctic. To this end we use the Arctic Subpolar Gyre State Estimate (ASTE; Nguyen et al. 2017), which is derived from a data-constrained model solution.

In contrast to unconstrained "forward" simulations (e.g., Holloway et al. 2007; Ilicak et al. 2016), ASTE is constrained by diverse streams of in situ and satellite observations. This provides higher confidence in the model's ability to represent water mass properties and the circulation in the Arctic Ocean (Nguyen et al. 2011; Wunsch and Heimbach 2013b; Fenty et al. 2017; Nguyen et al. 2017; Buehner et al. 2018). To the extent that ASTE can approximate the mean state of the Arctic Ocean and sea ice, consistent with the observations [to within the estimated uncertainty range (Fig. 3; Nguyen et al. 2011)], it serves as a "best guess" framework for our synthetic float simulations and quantification of errors.

This manuscript is organized as follows: section 2 describes ASTE and provides a brief assessment of quantities relevant to the synthetic float simulations. It further develops a methodology to track synthetic Argotype float trajectories under ice and defines metrics to quantify error in float positions and resulting hydrographic measurement uncertainties. Section 3 presents geographic maps of uncertainty in hydrographic measurements, and of likelihood of float surfacing. Section 4 summarizes our findings and provides an outlook.

\section{Methodology}

\section{a. Model description}

The primary modeling framework used in this investigation is ASTE, which leverages modeling and data assimilation capabilities developed within the Estimating the Circulation and Climate of the Ocean (ECCO) consortium (Wunsch and Heimbach 2007, 2013a; Forget et al. 2015a; Nguyen et al. 2017). The underlying model is the Massachusetts Institute of Technology general circulation model (MITgcm; Marshall et al. 1997; Adcroft et al. 2004). ASTE's domain covers the Arctic, all of its surrounding seas (Bering, Barents, Kara, Nordic, Labrador), the Canada Archipelago, and the entire Atlantic Ocean north of $-35^{\circ} \mathrm{N}$. The open boundaries are at $-35^{\circ} \mathrm{N}$ in the South Atlantic, $48.6^{\circ} \mathrm{N}$ in the Pacific, and at the Gibraltar Strait. The rationale for choosing a large domain for ASTE rather than limiting it to the Arctic Mediterranean is to enable important science questions pertaining to the connectivity between the subtropical and subpolar North Atlantic on the one hand, and the Arctic Ocean on the other hand on interannual to decadal time scale within a dynamically and kinematically closed framework. Moving the open boundary well south of Bering Strait in the North Pacific was done to incorporate much of the seasonally icecovered Pacific sector within ASTE. The model's nominal horizontal grid spacing in the Arctic is $\sim 15 \mathrm{~km}$, with 50 vertical levels. Initial guesses for the ocean's vertical mixing and sea ice parameters in the Arctic are taken from Nguyen et al. (2011). 

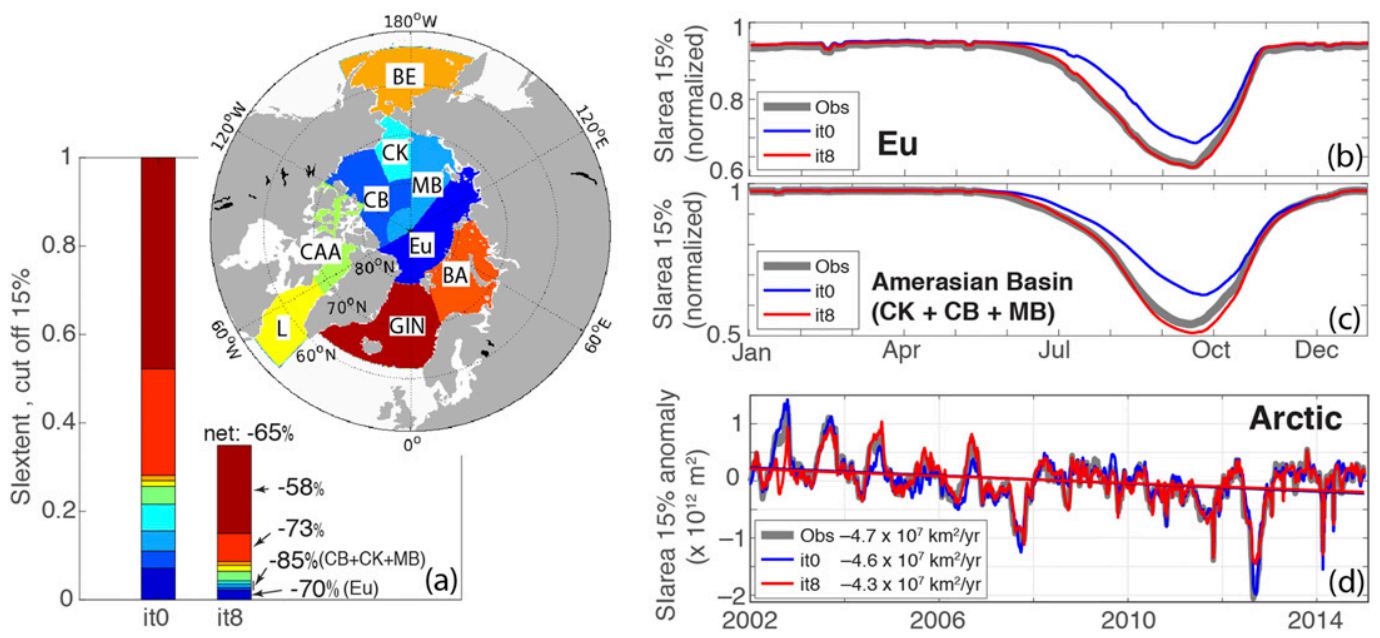

FIG. 3. (a) Reduction of misfits in sea ice concentration (ASTE minus observed) after eight iterations, broken down by geographic region. The numbers for it 8 are the percentages of misfit reduction: $65 \%$ net reduction broken down into $58 \%$ for the Greenland-Iceland-Norwegian Seas (GIN), 73\% for the Barents Sea (BA), $85 \%$ for the combined Canada-Chukchi-Makarov Basins (CB + CK + MB), and 70\% for the Eurasian Basin (Eu). Sea ice area above $15 \%$ for the (b) Eurasian and (c) Amerasian Basins, and (d) sea ice anomaly trends. The reduction of misfits is achieved through adjustments to input atmospheric forcing (Fenty and Heimbach 2013). Observations are from the EUMETSAT Ocean and Sea Ice Satellite Application Facility (OSISAF; Eastwood et al. 2011).

As discussed in Holloway et al. (2007), many state-ofthe-art Arctic Ocean models exhibit a subsurface AW circulation in anticyclonic sense in contrast to observations. The nominally $1^{\circ}$ horizontal-resolution global ocean-state estimate ECCO, version 4, release 3 (ECCOv4r3; Forget et al. 2015a), due to its focus being more at the lower latitudes, has the same reverse circulation in the Arctic (not shown). As a result, instead of using ECCOv4r3 for initial conditions, ASTE was first initialized from the World Ocean Atlas 2013 (Locarnini et al. 2013; Zweng et al. 2013) and optimized based on velocity at Fram Strait to ensure a cyclonic sense of circulation. Sea ice initial conditions come from the University of Washington Polar Science Center climatology for January 2002 (Zhang and Rothrock 2003). Farther south in regions where there were Argo and satellite sea surface height and temperature coverage, ECCOv4r3 is in good agreement with the observations. As a result, the lateral open boundary conditions for ASTE are taken from ECCOv4r3.

The surface boundary forcing comes from the 3-hourly Japanese 55-year Reanalysis (JRA-55; Kobayashi et al. 2015). Monthly mean estuarine fluxes of freshwater are based on the Regional, Electronic, Hydrographic Data Network for the Arctic Region (R-ArcticNET) dataset (Lammers and Shiklomanov 2001; Shiklomanov et al. 2006).

ASTE is formally fit to observations through a gradientbased iterative least squares minimization of the modeldata misfit that takes into account data and model uncertainties (Nguyen et al. 2017). The gradient with respect to a high dimensional space of uncertain input variables, referred to in the following as control variables, is obtained via the adjoint of the model, derived by means of algorithmic differentiation (AD; Giering and Kaminski 1998; Heimbach et al. 2005). Control variables in ASTE, which the model requires as input fields and which are subject to adjustment through the iterative minimization, are three-dimensional initial temperature and salinity, time-mean internal mixing fields [i.e., the lateral Gent-McWilliams (GM) and Redi coefficients and vertical diffusivity; Forget et al. 2015b], and time-evolving two-dimensional atmospheric forcing fields (Forget et al. 2015a).

The observational backbone used to constrain ASTE includes the standard ECCO in situ and satellite data for the subpolar gyre and North Atlantic (Forget et al. 2015a), and a dedicated high-latitude dataset that has been updated from Nguyen et al. (2011) to include ITP data (Krishfield et al. 2008), and mooring data in the Beaufort Sea (Proshutinsky et al. 2009), at Bering Strait (Woodgate 2018), Davis Strait (Curry et al. 2014), and Fram Strait (Beszczynska-Möller et al. 2012), as well as from the NABOS project (Pnyushkov et al. 2013). The state estimate covers the period 2002-15, coinciding with the era of satellite gravimetry (Tapley et al. 2019) and of Argo profiling floats (Riser et al. 2016).

\section{b. Assessment of the ASTE solution}

Before using ASTE for conducting Argo-type float simulations, we assess the reduction of model-data 

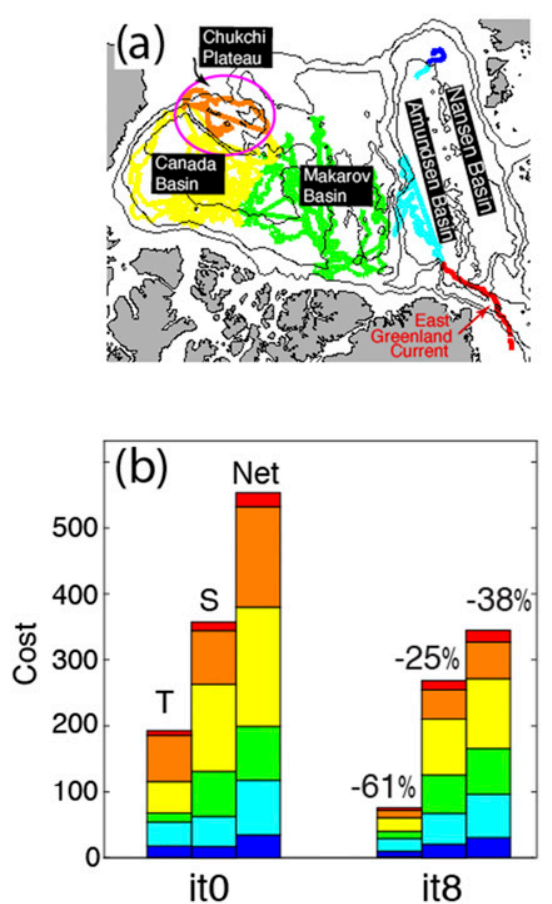
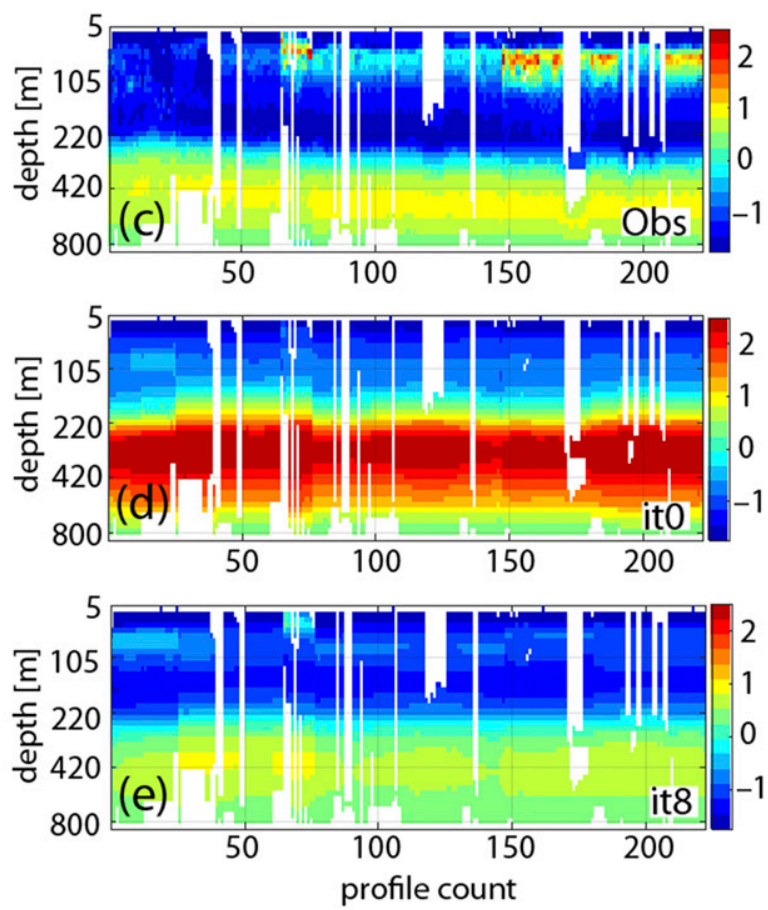

FIG. 4. (a) Spatial distribution of ITP data and (b) reduction of ASTE misfits in temperature and salinity of $61 \%$ and $25 \%$, respectively, for a net reduction of $38 \%$, after eight iterations. Colors in (b) represent the five regions labeled in (a). Vertical temperature of all profiles covering the Chukchi Plateau from (c) ITP, (d) iteration 0, and (e) iteration 8. The large misfits of the warm Atlantic Water core at depths 200-600 $\mathrm{m}$ in iteration 0 are due to excessive heat flux upstream at Fram Strait. With a combination of adjustments in initial conditions, vertical mixing, horizontal eddy stirring, and horizontal dissipation fields, the model at iteration 8 improves significantly in the core AW temperature representation.

misfits of sea ice concentration (Fig. 3) and Arctic hydrography (Fig. 4) that result from the gradient-based optimization. A number of factors, including uncertain atmospheric forcings, contribute to excessive sea ice in the marginal ice zones (e.g., the Chukchi and Greenland Seas) in the unconstrained simulation (it0) compared to satellite observations. Observed sea ice concentrations themselves have errors between $5 \%$ and $20 \%$ and the algorithms used to retrieve remotely sensed sea ice concentration frequently misidentify thin ice as open ocean (e.g., Ivanova et al. 2015). Fenty and Heimbach (2013) and Fenty et al. (2017) show that small adjustments to surface atmospheric fields, that is, with magnitudes within the spread of different atmospheric reanalysis products, can bring the simulated ice edge into agreement with the observations.

This study was carried out using the ASTE solution at its latest iteration at the time, iteration 8 , which provided a reasonable cost function reduction and warranting the use of the solution. After 8 iterations, the misfit in observed versus simulated sea ice concentration has been reduced by $\sim 65 \%$. In the subsurface, adjustments of a combination of initial conditions and model internal mixing parameters has brought ASTE temperature and salinity $(T, S)$ profiles closer to ITP observations, achieving a misfit reduction of $61 \%$ in $T$ and $25 \%$ in $S$ (Fig. 4; Nguyen et al. 2017). The unconstrained simulation (it0) has AW core temperatures that are too high downstream at the Chukchi Plateau region compared to ITP data (Figs. 4c,d). Previous studies (e.g., Holloway et al. 2007; Ilicak et al. 2016; Grist et al. 2018; Docquier et al. 2019) have shown that obtaining reasonable representations of $\mathrm{AW}$ layer thickness, mean flow, and core temperature is a difficult task with current state-of-the-art models due to various factors. These include a lack of constraints upstream of Fram Strait of both water current and hydrographic measurements, as well as along the incoming AW path between the Fram Strait and the NABOS mooring arrays (Fig. 4a).

For subsurface ocean currents, the Fram Strait mooring data (Beszczynska-Möller et al. 2012) is the primary constraint for volume and heat fluxes of Atlantic Water into the Arctic. After 8 iterations, the solution achieves a net reduction of $78 \%, 49 \%$, and $21 \%$ in temperature, salinity, and northward velocity misfits, respectively (not shown). 

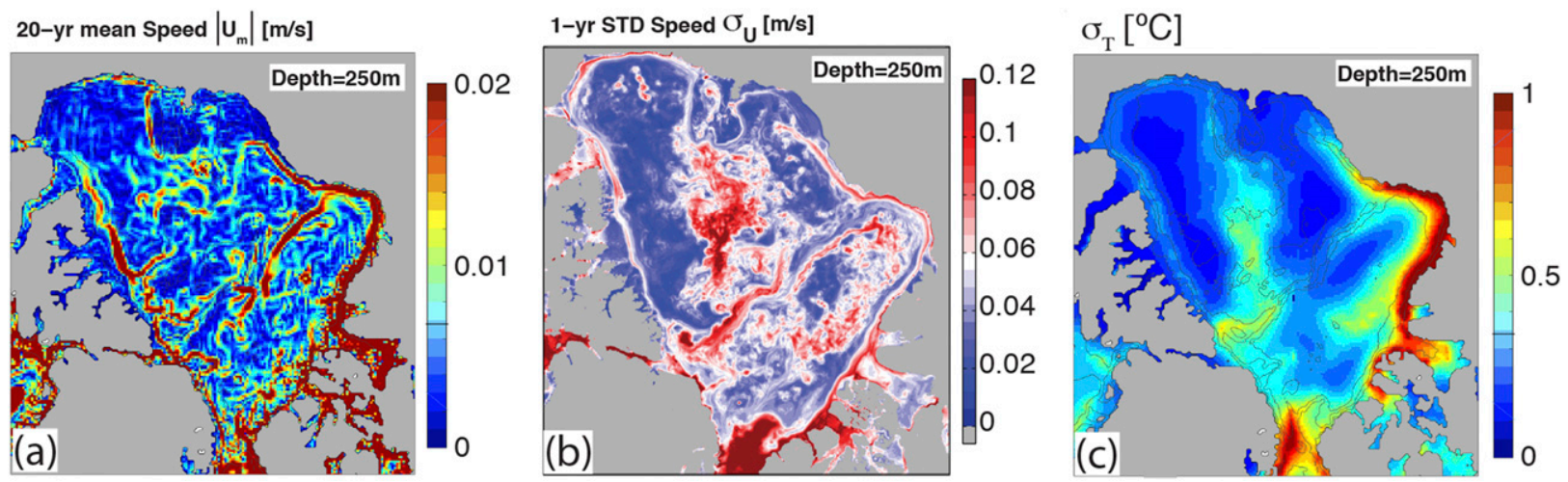

FIG. 5. (a) Mean 2002-15 ocean speed $\left|\mathbf{U}_{m}\right|$ at depth $250 \mathrm{~m}$. (b) 1-yr standard deviation of ocean speed from the high-horizontalresolution model (see text), to be added to the 14-yr ASTE ocean speed standard deviation to form $\boldsymbol{\sigma}_{\mathbf{U}}$. (c) Uncertainty in ocean temperature at depth $250 \mathrm{~m}$. This uncertainty includes both uncertainty in the currently available observations and model representation error. As the model resolution increases, the representation error is expected to decrease. However, there is a trade-off between this decrease and the requirement to have enough observations to resolve a larger number of grid points. Thus, the uncertainty will remain high due to this trade-off, until observations on a continuous spatial and temporal scale can be obtained. Note that observations in space alone can contain temporal biases that will also map into the representation uncertainty.

\section{c. Trajectory approximation and error quantification}

The development of an approximation for the ocean time-mean and time-varying flow fields in the absence of observations is nontrivial. Given that ocean observations are typically hydrographic properties, the connection between the real and simulated world is made using ASTE. We assume that the real ocean state (denoted with the superscript $\rho$ ) is described by the time-evolving and spatially varying fields of velocity $\mathbf{U}^{\rho}[\mathbf{x}(t)]$ and active tracers, (i.e., $T$ and $\left.S\right) \Omega^{\rho}[\mathbf{x}(t)]$. The model (superscript $\mu$ ) approximates these fields by solving a set of primitive equations to obtain $\mathbf{U}^{\mu}[\mathbf{x}(t)]$ and $\Omega^{\mu}[\mathbf{x}(t)]$.

In contrast to the larger number of tracer observations $\Omega^{\rho}$, continuous velocity observations $\mathbf{U}^{\rho}$ are extremely scarce, except for a small number of mooring locations. Holloway et al. (2007) have shown that it is quite possible for models to reasonably represent the hydrography in the Arctic Ocean while simulating circulations in reverse among models. For these reasons, $\mathbf{U}^{\mu}$ is less constrained than $\Omega^{\mu}$. To the extent that ASTE is able to minimize the misfits between $\Omega^{\rho}$ and $\Omega^{\mu}$, we make the assumption that the time-mean flow field of $\mathbf{U}^{\mu}$ in ASTE is representative of the large-scale true ocean currents. That is, we seek a representation of $\mathbf{U}^{\mu}$ to advect simulated floats and quantify uncertainty in hydrographic quantities associated with the floats' unknown positions during silent time.

Because present-day real trajectories of underice floats in the Arctic and their associated hydrographic measurements are not yet available, we use the simulated flow field underlying ASTE, $\mathbf{U}^{\mu}[\mathbf{x}(t)]$, to model float trajectories in a reference simulation, and treat $\Omega^{\mu}[\mathbf{x}(t)]$ as "true" measurements for the purpose of uncertainty quantification. Note that we make no claim that the full modeled flow field is representative of the real flow field, but that the large-scale component is. We hence develop a mathematical formulation for uncertainty quantification based on a reduced form of the velocity field. For clarity, we drop the superscript $\mu$ in the following derivation because we work only in the modeling space at this point.

The position $\mathbf{x}(t)$ of a float at any given time is given by the full flow field:

$$
\begin{aligned}
\frac{d \mathbf{x}(t)}{d t} & =\mathbf{U}[\mathbf{x}(t)], \\
\mathbf{x}(0) & =\mathbf{x}_{0},
\end{aligned}
$$

where $\mathbf{U}[\mathbf{x}(t)]$ is the full 3D flow field obtained from the ASTE solution. The first approximation we made is that, because the time-mean vertical velocity component is much smaller than the horizontal components, we choose to neglect it and reduce $\mathbf{U}[\mathbf{x}(t)]$ to contain only the horizontal velocity. Note, however, that these horizontal components are fully defined in 3D space. In addition, because the modeled flow field is not observationally well constrained, we assume that $\mathbf{U}[\mathbf{x}(t)]$ is a random variable with normal probability distribution, which is fully specified by its time mean and time variance:

$$
\tilde{\mathbf{U}}(\mathbf{x}) \approx N\left[\mathbf{U}_{m}(\mathbf{x}), \boldsymbol{\sigma}_{\mathbf{U}}(\mathbf{x})\right]
$$

where $\mathbf{U}_{m}(\mathbf{x})$ is the 14-yr (2002-15) climatological mean (Fig. 5a) and $\boldsymbol{\sigma}_{\mathbf{U}}(\mathbf{x})$ is the spatially varying 14-yr standard deviation of $\mathbf{U}[\mathbf{x}(t)]$. At each grid point in 3D space, 
$\boldsymbol{\sigma}_{\mathbf{U}(\mathbf{x})}$ is a $2 \times 2$ diagonal matrix, that is, the two components of the horizontal velocity field at that grid point can vary independently. Because ASTE's horizontal grid spacing does not resolve the first baroclinic deformation radius, which in the Arctic is of order $2-15 \mathrm{~km}$ (Nurser and Bacon 2013), $\boldsymbol{\sigma}_{\mathbf{U}}(\mathbf{x})$ is derived from a velocity variance field of a 1-yr very high-resolution (of order $1 \mathrm{~km}$, Fig. $5 \mathrm{~b}$ ) forward simulation (Wang et al. 2018; Torres et al. 2018). The approximate position of a float is then derived from

$$
\frac{d \tilde{\mathbf{x}}(t)}{d t}=\tilde{\mathbf{U}}
$$

subject to the initial condition $\tilde{\mathbf{x}}\left(t=t_{\text {surface }}\right)=\mathbf{x}\left(t=t_{\text {surface }}\right)$ where $t=t_{\text {surface }}$ is the time when a float surfaces and reports its position. Note that since $\tilde{\mathbf{U}}$ is a random variable, with distribution specified by Eq. (2), the approximate trajectory $\tilde{\mathbf{x}}(t)$ is a random variable as well. The error functions for position and hydrographic properties $\Omega$ while the floats are not able to surface are defined as

$$
\begin{aligned}
& e_{\mathbf{x}}=\sqrt{\left[\frac{\mathbf{x}(t)-\tilde{\mathbf{x}}(t)}{\sigma_{\mathbf{x}}}\right]^{2}}, \\
& e_{\Omega}=\sqrt{\left\{\frac{\Omega[\mathbf{x}(t)]-\tilde{\Omega}[\tilde{\mathbf{x}}(t)]}{\sigma_{\Omega}}\right\}^{2}},
\end{aligned}
$$

where $\tilde{\Omega}[\tilde{\mathbf{x}}(t)]$ is the hydrographic values along the approximate trajectory $\tilde{\mathbf{x}}(t)$. The quantity of interest is $e_{\Omega}$ because it provides a measure of how error in hydrographic measurements will grow in time when the positions are unknown; $\sigma_{\Omega}$ is the hydrographic uncertainty derived from existing measurements and model representation errors, and is updated from Forget and Wunsch (2007) and Fenty and Heimbach (2013). Figure 5c gives an example of $\sigma_{\Omega=\theta}$ at $250 \mathrm{~m}$ depth, where $\theta$ is the potential temperature. As $\tilde{\mathbf{x}}(t)$ is a realization derived from $\tilde{\mathbf{U}}$, a large number of samples $\tilde{\mathbf{x}}(t)$ are needed to approximate the error in estimating $\mathbf{x}(t)$. For $N$ samples, the mean error is calculated as

$$
\bar{e}_{\Omega}=\frac{1}{N} \sum_{i=1}^{N}\left(e_{\Omega}\right)_{i}
$$

To investigate depth-dependent errors, three depth ranges are considered (Fig. 6): 0-100, 100-300, and $300-2000 \mathrm{~m}$.

Note that even though we reduced the flow to a timemean $\mathbf{U}_{m}(\mathbf{x})$ and used the eddy-resolving variability $\boldsymbol{\sigma}_{\mathbf{U}}(\mathbf{x})$ to estimate the flow field [Eq. (2)], the $T$ and $S$ fields remain fully time evolving. The primary reason for this choice is that, as we have argued above, the flow

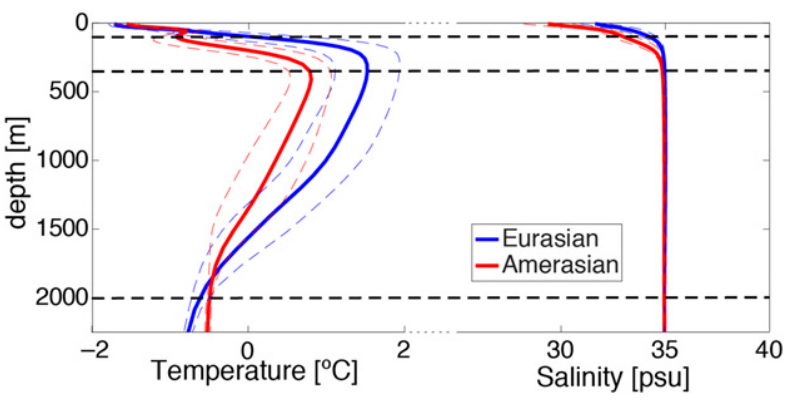

FIG. 6. Mean (solid) and standard deviation (dashed) of modeled vertical temperature and salinity profiles for the Amerasian (red) and Eurasian (blue) Basins. Dashed black horizontal lines separate the three layers used in the error analyses. The depth ranges are 0-100, 100-300, and 300-2000 m.

field is much less constrained than the time-evolving hydrography in ASTE. Furthermore, a comparison of the standard deviations of ASTE's time-evolving $\Omega$ fields with $\sigma_{\Omega}$ derived from the high-resolution model reveals that the former does not underestimate the latter, showing no systematic bias with respect to $\sigma_{\Omega}$ throughout the water column. Spatially, in some regions, including most of the Arctic interior, ASTE's $\Omega$ standard deviations are larger, while in other regions they are smaller by, on average, a factor of 3 or less. This suggests that ASTE time-evolving $T$ and $S$ fields capture most of the high-resolution hydrographic variability. For this reason, we did not consider adding more complexity to $\tilde{\Omega}[\tilde{\mathbf{x}}(t)]$ in Eq. (5).

Last, we note that the contribution of errors induced by water column shear as the floats ascend/descend is not considered here. This is because, as discussed above, the full mean 3D currents in the Arctic, and thus their vertical shear, are not well constrained. Consequently, any uncertainty estimated from the not well constrained shear will incur additional systematic errors.

\section{d. Experiment setup}

Step 1: In a reference experiment, denoted RunREF, 681 synthetic floats were seeded uniformly throughout the deep Arctic Basin at every fourth grid point where the ocean depth is greater than $2000 \mathrm{~m}$, Fig. 7, black squares, and programmed to collect data every 10 days as they drift passively, advected by the simulated velocity $\mathbf{U}(t)$ over a 5 -yr period beginning 1 January 2007. The Argo float's lifetime is 4-5 years (Roemmich et al. 2009, 2019). In the Arctic, even though sea ice can cause damage to shorten the life of the floats, a refined sea ice detection algorithm has proven successful in helping to extend their life (Klatt et al. 2007; Chamberlain et al. 2018). Here, we use a simulated lifetime of 5-yr for error calculation. The parking depth used in this experiment is the 

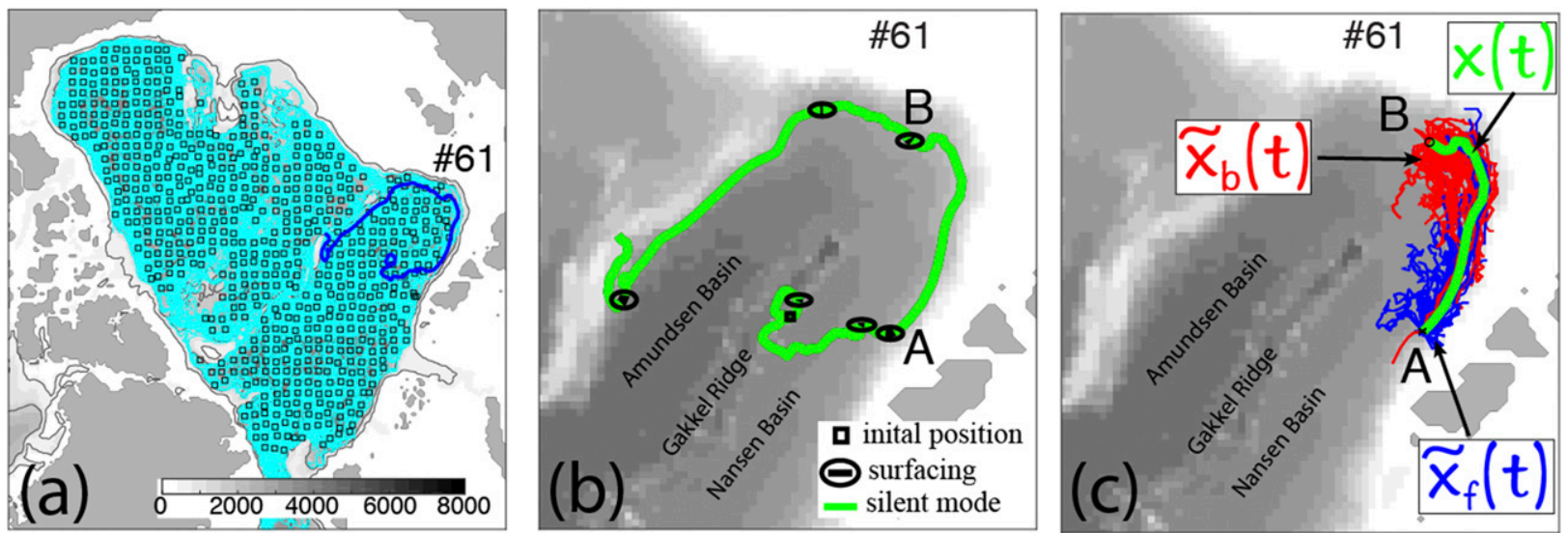

FIG. 7. (a) Geographic distribution of the 681 seeded floats (black squares) and all their true trajectories (cyan) over the 5-yr simulation in RunREF. Within the 5-yr period, the trajectories cover nearly the entire deep Arctic Basin such that $92 \%$ of the model grid points have at least one float transiting through. (b) A zoom-in of float 61 showing segments of surfacing (black oval and line) and silent mode (green), and (c) examples of the true $\mathbf{x}(t)$ (green), forward-tracked $\tilde{\mathbf{x}}_{\mathbf{f}}(t)$ (blue), and backward-tracked $\tilde{\mathbf{x}}_{\mathbf{b}}(t)$ (red) trajectories for silent segment A-B. Tracking begins forward in time from the moment the float starts its silent trajectory (at point A) and backward in time from the next moment the float resurfaces (at point B). $m=100$ is the number of offline floats being used in each tracking algorithm, yielding a total of $2 \times m$ paths per silent mode (underice) segment.

conventional Argo parking depth of $1000 \mathrm{~m}$. The referencerun trajectories $\mathbf{x}(t)$, hydrographic profiles $\Omega[\mathbf{x}(t), z, t]$, and sea ice concentration $\operatorname{SIc}(\mathbf{x}, t)$ are treated as "data."

Step 2: The float-seeding experiment was repeated 200 times, with the simulated flow field $\mathbf{U}[\mathbf{x}(t)]$ replaced at each model time step ( $20 \mathrm{~min}$ in this case) with an offline flow field $\tilde{\mathbf{U}}(\mathbf{x}, t)$ constructed as follows:

$$
\tilde{\mathbf{U}}(\mathbf{x}, t)=\mathbf{U}_{m}(\mathbf{x})+A(t) \boldsymbol{\sigma}_{\mathbf{U}}(\mathbf{x})
$$

where $A(t)$ is a time-varying scalar drawn from the uniform random distribution over the interval $[-1,1]$. A float at any position $\mathbf{x}$ is then being advected from its current position to the next by the velocity field $\tilde{\mathbf{U}}(\mathbf{x}, t)$. In this manner, trajectories of all 681 floats $\times 200$ simulations are obtained through the 5-yr period, covering the entire Arctic Basin. The larger the number of offline simulations, the higher the likelihood of having enough floats crossing each model grid point within the 5-yr simulation to build robust three-dimensional geographical statistics.

Step 3: The error accumulation is calculated as follows. Each of the 681 synthetic floats from the RunREF, for example, float 61 in Fig. 7, is allowed to "surface" if sea ice concentration $\operatorname{SIc}(\mathbf{x}, t)$ falls below a certain threshold $\alpha$ (that needs to be chosen). At each point where the float surfaces, its position is known, time $t$ is reset to 0 , and all approximate positions are reset to the true position, that is, $\tilde{\mathbf{x}}(0)=\mathbf{x}(0)$. The float continues to collect data and surface along its trajectory until sea ice concentration rises again and reaches $\operatorname{SIc}(\mathbf{x}, t)>\alpha$. At this time, out of the synthetic floats generated in step 2, $m$ are selected that are closest to float 61 at the time of diving (point $\mathrm{A}$ ), and another $m$ are selected that are closest to the position at the time of subsequent resurfacing (point B).

Two tracking algorithms follow the two sets of $m$ sample floats for the entire time that the float remains in silent mode between points $\mathrm{A}$ and $\mathrm{B}$. Note that the sample trajectories are calculated based on the offline flow field computed in Eq. (7). In the example of float 61, the silent section connects points A and B in Fig. 7c. The forward tracking algorithm selects the closest $m=100$ floats to point $\mathrm{A}$ at the time of diving and follows them forward in time, whereas the backward tracking algorithm performs the reverse task, that is, finding the $m=$ 100 closest floats to point B at the time of surfacing and tracking them backward in time to where they came from. Thus, there are a total of $2 \times m$ paths whose $\tilde{\Omega}[\tilde{\mathbf{x}}(t)]$ are recorded for calculation of the accumulated $e_{\Omega}$.

Finally, the $q$ paths with the lowest error are used to compute the average $\bar{e}_{\Omega}$ per float and per silent section. Here, $q$ ranges between a minimum of 2 and maximum of $2 \times m$ paths, with smaller $q$ capturing paths that are most likely to connect points A and B. As $q$ increases, paths are included that have increasingly negligible probability of connecting A and B and would result in large biases in the estimated errors. For our statistical analyses, we set $q=$ $m=100$, that is, we choose half the combined forward and backward trajectories. The hydrographic measurements are defined as "useful" if their $\bar{e}_{\Omega} \leq 1$.

The longer the float drifts under ice, the larger the silent trajectory and its associated hydrographic errors. 


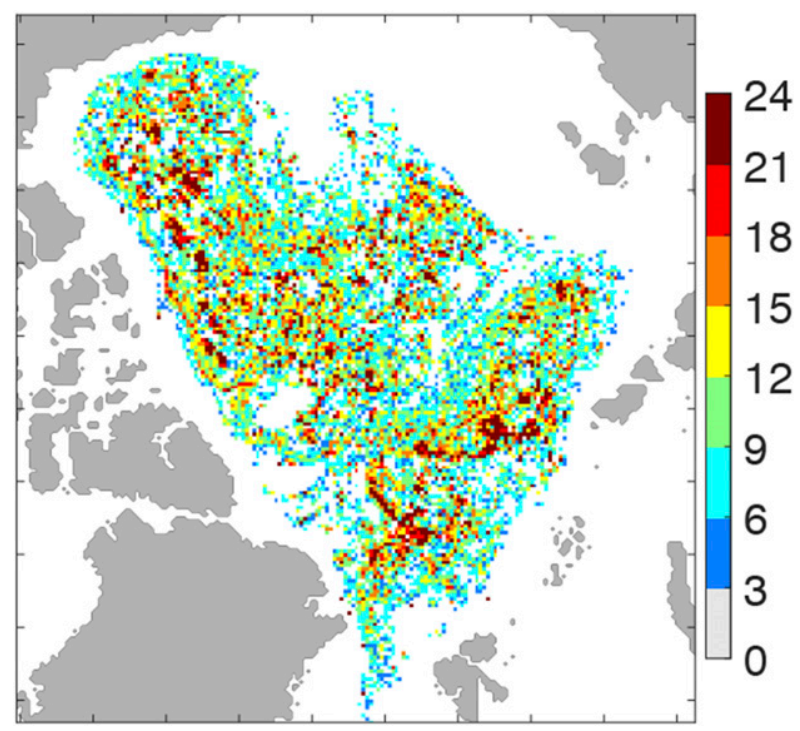

FIG. 8. Number of measurements in each model grid box at any depth between 0 and $2000 \mathrm{~m}$ during the 5 -yr RunREF simulation. Only grid boxes that have at least $N_{\text {cutoff }} \geq 5$ contribute to the three-dimensional error calculation. $72 \%$ of the deep Arctic Basin area satisfies this $N_{\text {cutoff }}$ constraint, with a range of $92 \%$ for $N_{\text {cutoff }}=1$ to $41 \%$ for $N_{\text {cutoff }}=10$.

In addition, if the float drifts through a region with large $\boldsymbol{\sigma}_{\mathbf{U}}$, errors in trajectory and hydrography are also expected to be large.

Step 4: The three-dimensional field of mean hydrographic error $\bar{e}_{\Omega}$ derived from silent sections of all 681 seeded true floats and their $200 \times 681$ randomized paths, is used to build geographical statistics for the three layers covering depth ranges $0-100,100-300$, and $300-2000 \mathrm{~m}$. The time dimension is collapsed to obtain time-mean maps of trajectory deviations, hydrographic errors, and expected surfacing frequency.

During the 5-yr simulation, the 681 true floats in RunREF were advected along with the ocean currents resulting in $92 \%$ of the model grid boxes in the deep ocean having at least one hydrographic measurement. To build the three-dimensional statistics, only grid boxes that have at least $N_{\text {cutoff }}=5$ measurements over the whole simulation period were used. This $N_{\text {cutoff }}$ constraint results in $72 \%$ of the deep Arctic Basin area being used. Figure 8 shows a map of locations where there are $N_{\text {cutoff }} \geq 5$ at each depth in the water column above $2000 \mathrm{~m}$.

It is likely that there is a seasonal cycle embedded within the time-mean error statistics; however, such time-dependent decomposition would require a significantly higher number of true floats to achieve robust statistics for each of the months within the seasonal cycle. As discussed in subsequent sections, much information can already be extracted from the time-mean, three-dimensional error map derived here.
We note that even though the $N_{\text {cutoff }}$ used here is relatively low, this is only the minimum number of hydrographic measurements, and for each of them, at any given time, there are $m \times 2=200$ simulated forward and backward float trajectories that contribute to its error calculation [see Eqs. (5) and (6)]. We note also that the number of 681 true floats and their initial spatial distribution have been chosen for calculating a robust gridpointwise error statistics and do not reflect the optimal number or distribution of Arctic Argo floats.

The error calculation also depends on the choice of parameter $\alpha$, warranting a discussion of its meaning in context of sea ice leads and other sea ice thresholds established in the literature. The $\alpha$ threshold used in step 3 represents the open-water fraction at the ice margins rather than the thin and long openings surrounded by near $100 \%$ sea ice concentrations known as "leads" that can be detected from satellite (e.g., Murashkin et al. 2018; Hoffman et al. 2019) or the sea ice detection threshold used by Klatt et al. (2007) to determine when the float should surface. Klatt et al. (2007) showed that a very conservative sea ice detection algorithm can significantly prolong the lifetime of the floats. By not resolving leads, the simulations can be interpreted as not taking leads into account for surfacing opportunities, which fits with Klatt et al. (2007) conservative criterion as leads can open and close quickly during the time the floats are at or near the surface. A "conservative" threshold for $\alpha$, however, does not imply that the entire grid has to have little sea ice. At ASTE horizontal grid spacing of $\sim 15 \mathrm{~km}$ in the Arctic (i.e., grid area of $225 \mathrm{~km}^{2}$ ), a range of decreasing $\alpha$ of $80 \%-50 \%$ would imply a required open-water area of $45-120 \mathrm{~km}^{2}$ along the ice edge for the float to surface, which is reasonably conservative. On the other hand, an $\alpha$ of $100 \%$ would be unrealistically restrictive for the $15 \mathrm{~km}$ resolution as it implies a large area of $225 \mathrm{~km}^{2}$ must be completely free of ice before a float is allowed to surface. We emphasize, however, that the range of the $\alpha$ threshold used here should be interpreted as a way to assess the range of possible errors given that the "real" error estimates are not achievable until there are enough real Arctic Argo floats.

\section{Results}

\section{a. Error quantification: Along trajectory}

At any given time along its path, a float is allowed to surface if the model grid's sea ice concentration SIc at the surface is at or below a certain threshold $\alpha$. The most strict threshold is $\alpha=0$ implying the grid box has to be $100 \%$ open water before the float can surface. However, given the model horizontal spacing of nominally $15 \mathrm{~km} \times 15 \mathrm{~km}$, a more practical set of values 
(a)
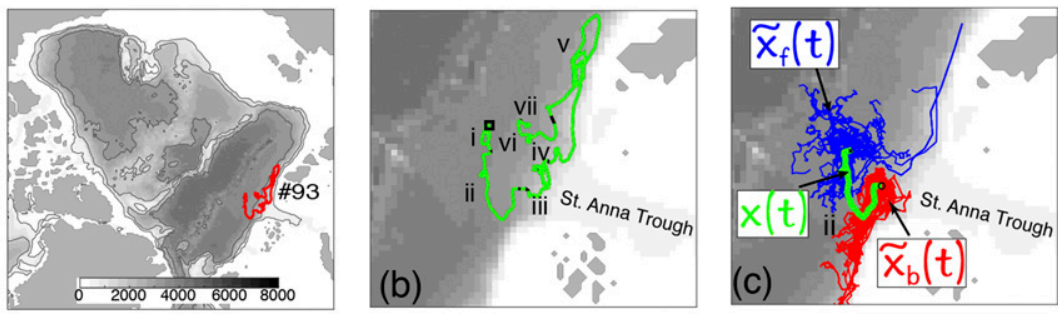

(d)

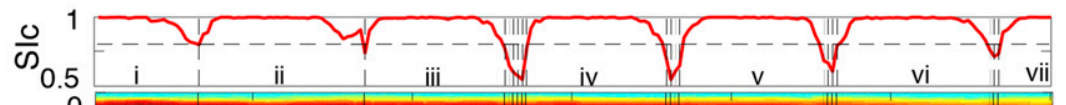

(e)

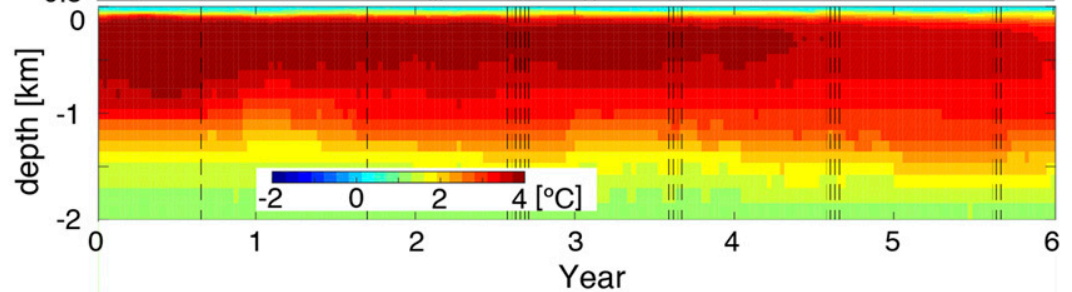

\section{(f)}

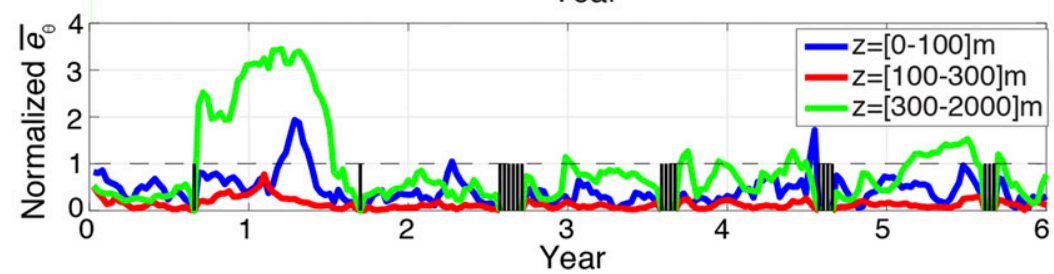

(g)

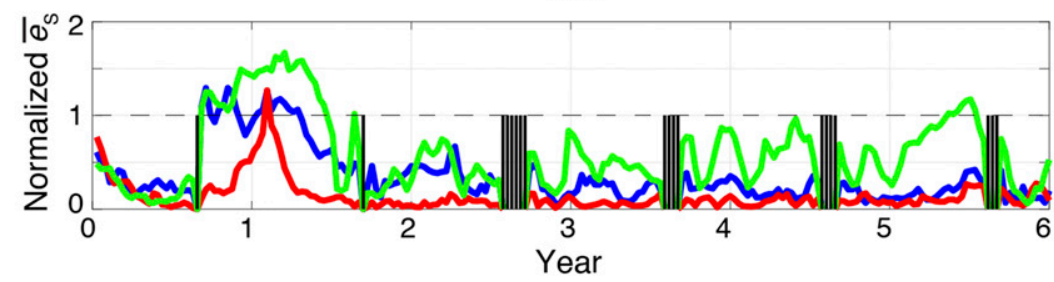

FIG. 9. (a) Location of float 93 true trajectory and (b) its seven silent-mode segments. (c) Forward- and backward-tracked trajectories for silent-mode segment ii. (d) Sea ice concentration (SIc) and (e) potential temperature $\theta$ along the float true trajectory. Normalized mean error $\overline{e_{\Omega}}$ for (f) $\Omega=\theta$ and (g) $\Omega=$ salinity, as calculated from Eq. (5). The errors are normalized by their respective uncertainties (Fig. 5c). The data are quantified as useful when $\overline{e_{\Omega}} \leq 1$ (horizontal dashed black). Vertical black dashed and solid lines in all panels mark when sea ice falls below the threshold $\alpha$, where in this example, set at 0.8 . Note that the unusually large temperature and salinity errors during year 1 in (f) and (g) are due to the floats' transit through an area of high eddying activity, where their trajectories can deviate from the mean flow within a short time.

$\alpha=[0.80,0.75,0.70,0.65,0.60,0.55,0.50]$, corresponding to $45-120 \mathrm{~km}^{2}$ of open water per grid box, is used here to assess the sensitivity of the hydrographic error $\overline{e_{\Omega}}$ to the choice of $\alpha$. Given that multiyear sea ice in the coming years is anticipated to decrease in comparison to the simulated years of 2007-13 (Kwok and Cunningham 2015), these thresholds can also be interpreted as variability in sea ice minimum, where $\alpha=0.8$ and $\alpha=0.5$ correspond to years of extreme low and high summer sea ice minimum.

We use synthetic float 93 for illustration purposes. Figure 9 shows normalized errors $\overline{e_{\Omega}}$ for potential temperature and salinity for this float based on $m \times 2=200$ samples of the combined backward- and forward-tracked trajectories. When the float surfaces, errors are reset to zero because the position of the float is known, whereas during silent time error accumulates along the trajectory. In the cases when the backward- and forward-tracked trajectories $\tilde{\mathbf{x}}(t)$ deviate significantly from the true trajectory $\mathbf{x}(t)$, or in the case when the float traverses a region with high variability in temperature and/or salinity (e.g., in regions of high eddy activity or high tracer gradients), $\overline{e_{\Omega}}>1$.

For the sample float 93, its trajectory starts in the interior of the Nansen Basin just north of the Saint Anna Trough, where dense Atlantic Water from the Barents Sea branch enters the Arctic (Figs. 1a and 9a; Rudels et al. 2004). 


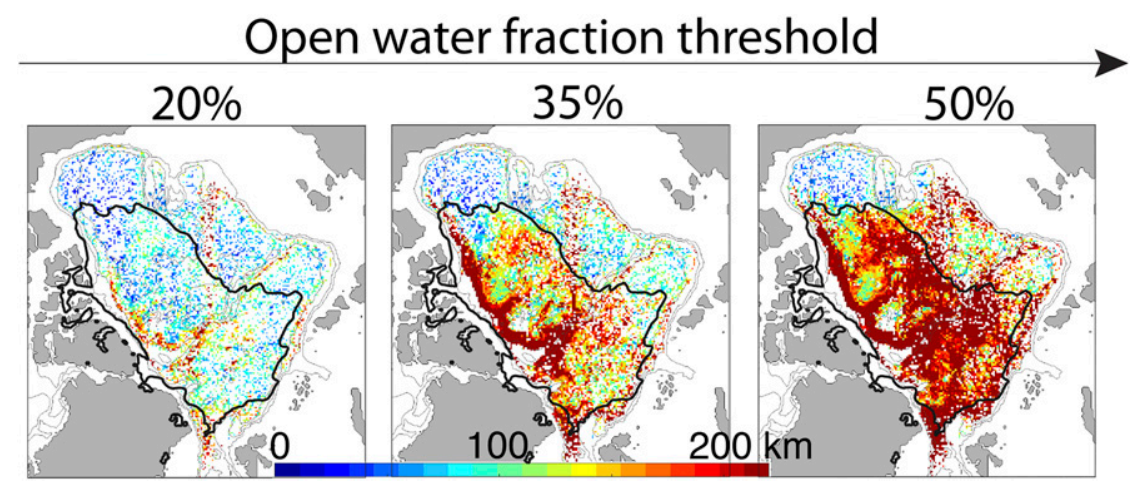

FIG. 10. Spatial distribution of mean separation distance between the true trajectories and their $m$ samples during silent time, as a function of the open-water threshold $1-\alpha$, where $\alpha$ is the sea ice fraction. When the open-water fraction in the model grid box increases from 0 to $1-\alpha$ (i.e., sea ice has decreased from 1 to $\alpha$ ), the float is allowed to surface. (right) For a more stringent threshold of $1-\alpha=0.5, \approx 50 \%$ of the grid is required to be open ocean in order for the float to be able to surface, thus requiring the floats to travel through a longer freezing season. (left) A more relaxed threshold of $\alpha=0.8$ implies only $20 \%$ of the grid is required to be open water before the float can already surface, thus allowing more surfacing time and less accumulated position errors. These thresholds are artificially chosen to illustrate the continuous nature of the error quantification and provide insights into the regions where one can expect higher chances of float surfacing (see also Fig. 13). (center) An intermediate threshold of $1-\alpha=0.35$. The black contour shows the minimum sea ice coverage for the period 2002-15.

The true, backward-, and forward-tracked trajectories are constrained to the basin interior, but with diverse loops that occasionally reach the midocean Gakkel Ridge separating the Nansen and the Amundsen Basins. Over the duration of the simulation, $\overline{e_{\Omega}}>1$ only during the first winter. This corresponds to the underice section ii in Fig. 9b, a section over which the backward trajectories are too uniformly traced to points westward upstream along the AW pathway instead of having enough variability to overlap with the true track. This suggests there exist cases when the simplified flow field $\tilde{U}$ underrepresents the variability of the true flow, likely by having $\boldsymbol{\sigma}_{\mathbf{U}}$ that is too low to allow more tracks to deviate from the mean path. In contrast, if the tracked paths are well defined, as they are for section A-B of float 61 in Fig. $7 \mathrm{~b}, \overline{e_{\Omega}}$ are expected to be small. Given that current state-of-the-art models still have misfits of up to several degrees Celsius [see Fig. 1 in Ilicak et al. (2016)], locations where $\overline{\bar{e}_{\Omega}}>1$ may still prove useful to constrain models.

\section{b. Error quantification: Spatial distribution}

The three-dimensional geographical distribution of $\overline{e_{\Omega}}$, as derived from silent sections of all the 681 seeded true floats and their $200 \times 681$ stochastically resampled paths, is obtained using the method outlined in section $2 \mathrm{~d}$, step 4 .

Figure 10 shows the mean distance between the $N$ samples $\tilde{\mathbf{x}}(t)$ and the true position $\mathbf{x}(t)$ as a function of the open-water fraction threshold $1-\alpha$. At any given geographic location, a large distance implies that if a float transits through the region, the ability to "predict" its trajectory will be low, possibly due to a combination of highly variable currents and high sea ice cover. For $\alpha=0.8$, only $20 \%$ open-water fraction in a grid box is required for the float to surface, the floats can surface much more often, and the mean separation distance remains under $100 \mathrm{~km}$ throughout the Arctic (left panel in Fig. 10). This can be viewed as an upper limit for a future Arctic Ocean with sea ice significantly thinner than at present, such that the ice can be easily deformed to form cracks, in combination with a longer melting season. For a more stringent threshold of $\alpha=0.5$, corresponding to $50 \%$ open-water fraction needed for the float to be able to surface, the mean separation distance doubles, and its spatial distribution follows closely the summer minimum sea ice cover. A few exceptions to the near overlap between spatial distribution of separation distance and sea ice minimum are seen in the Canada and Makarov Basins, north of the Canadian Archipelago. Here the model's $\boldsymbol{\sigma}_{\mathbf{U}}$ is low (Fig. $5 b$ ) such that the majority of both the true and sampled floats can quickly be advected out of the zone by the mean current, either toward the narrow and strong-flowing boundary region, or into an area of higher $\boldsymbol{\sigma}_{\mathbf{U}}$ such as north of the Chukchi Plateau.

Figure 11 shows the mean normalized error for salinity as a function of depth range and open-water fraction threshold $1-\alpha$. In the upper $100 \mathrm{~m}$ of the ocean, where variability in salinity is high (Nurser and Bacon 2013), spatial and temporal decorrelation length 


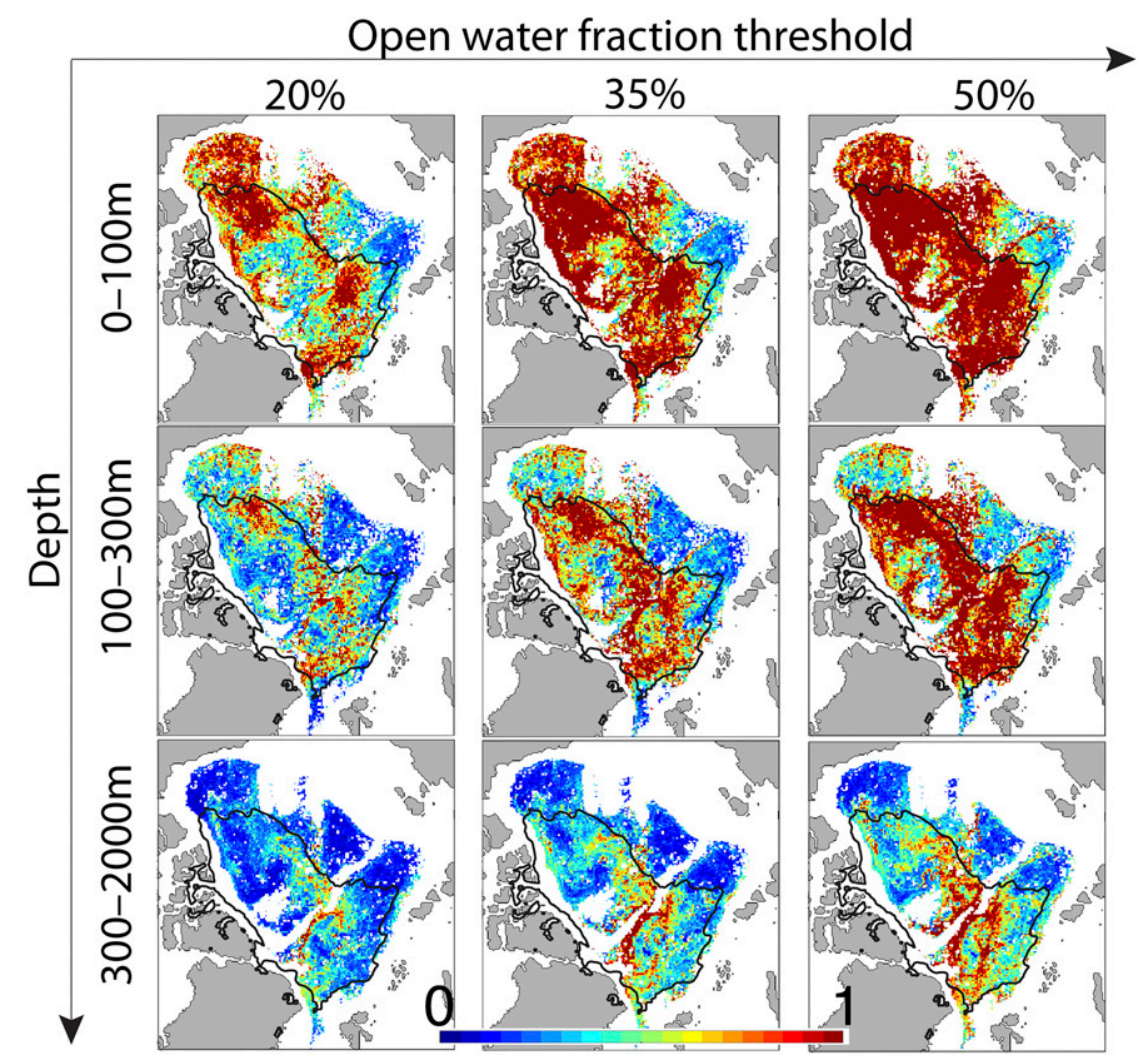

FIG. 11. Mean normalized salinity error $\overline{e_{S}}$, defined in Eq. (6), as a function of depth range and open-water fraction threshold $1-\alpha$. The black contour shows the mean minimum sea ice cover for the period 2002-15.

scales are expected to be smaller than the average separation distance the floats likely need to traverse before position can be reported. For this reason, $\overline{e_{S}} \geq 1$ throughout much of the Arctic interior at shallow depths. Two exceptions are the eastern Nansen Basin, connecting with the western Amundsen Basin, and southern Makarov Basin, where $\sigma_{S}$ is high. These places are either in the seasonal ice zone, over rough bottom topography at the shelf break, where eddy activity is expected to be high (Nurser and Bacon 2013), or in regions where high freshwater inputs from river runoff are expected seasonally. At depth ranges $100-300 \mathrm{~m}$, in addition to the regions with low errors mentioned above, the Chukchi-Beaufort shelf break in the Canada Basin also has $\overline{e_{S}}<1$. A key result is that in the interior Arctic below $300 \mathrm{~m}$, where correlation length scales in both space and time are larger (Nurser and Bacon 2013), the float measurements are "useful," with $\overline{e_{S}}<1$, nearly throughout the Arctic Basin, despite $\sigma_{S}$ being two orders of magnitude smaller than near the surface.

Errors in potential temperature associated with the floats' silent time (Fig. 12) are similar to those from salinity, with a key difference being the Nansen Basin in the vicinity of Fram Strait. This region has high current and hydrographic variability and exhibits extensive recirculation (Beszczynska-Möller et al. 2012), as seen from observations, high-resolution $\boldsymbol{\sigma}_{\mathbf{U}}$ map (Fig. 5b), as well as our simulated float trajectories. In this region, the $2 \times m$ forward- and backward-tracked trajectories based on $\tilde{\mathbf{U}}$ cannot capture the float's path over long silent periods with sufficient detail, resulting in high values of $\overline{e_{\theta}}$ (see float 93 in Fig. 9c).

In addition, the recirculation brings together various sources of Atlantic Water: the Fram Strait branch boundary current, the Nansen interior, and the dense overflow through the Saint Anna Trough (Rudels et al. 2004). Each of these branches has a distinct temperature and salinity signature (Rudels et al. 2004; BeszczynskaMöller et al. 2012; Pnyushkov et al. 2013), making ocean temperature highly variable and resulting in $\overline{e_{\theta}}>1$ at depth ranges $300-1000 \mathrm{~m}$.

Figure 13 shows the spatial distribution of mean time interval between surfacing events (i.e., places where the average number of days a float can be expected to spend without being able to surface, starting from or prior to arrival at a specific geographic location). This spatial pattern, as expected, resembles that of the annual 


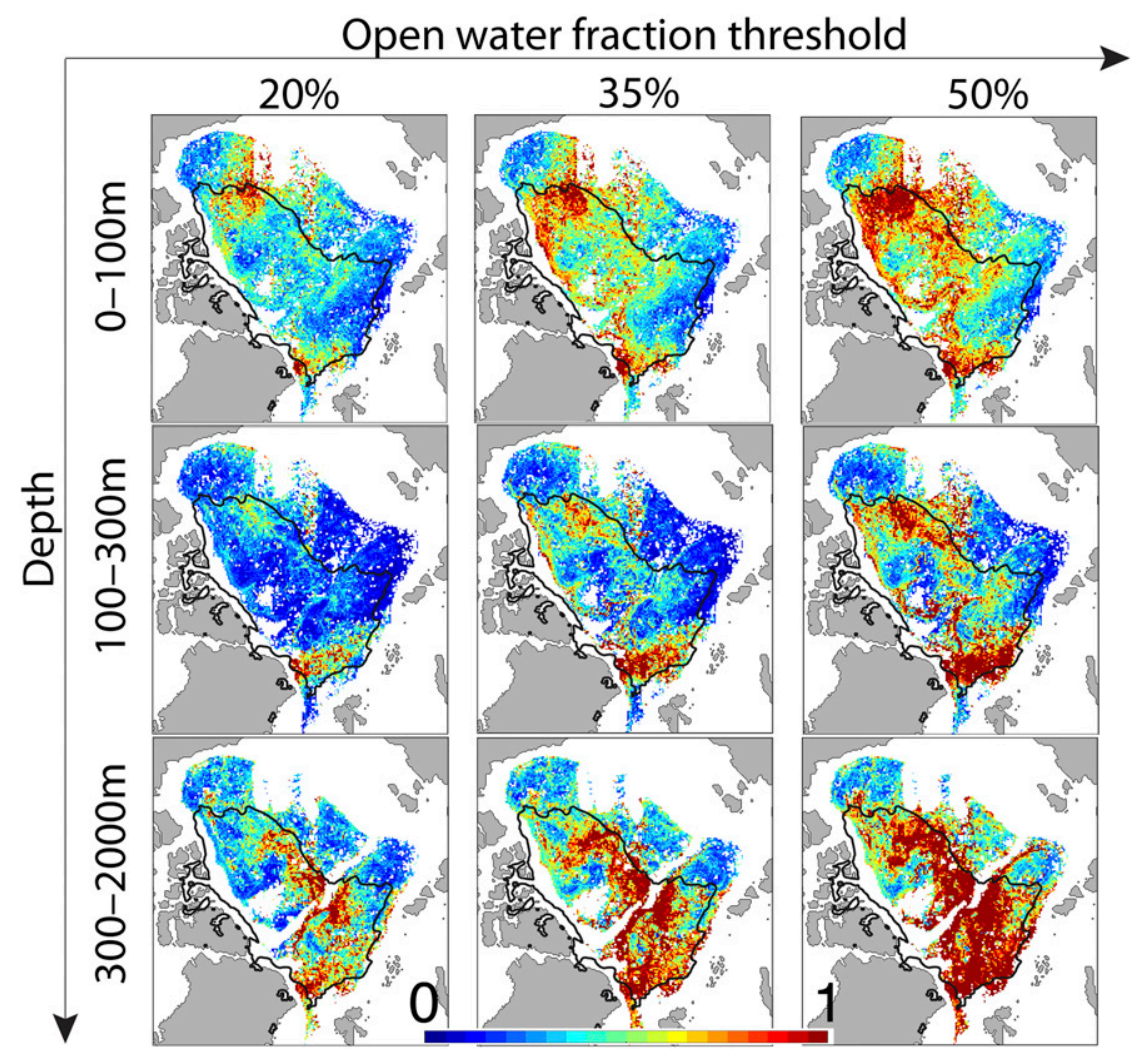

FIG. 12. Mean normalized potential temperature error $\overline{e_{\theta}}$, defined in Eq. (6), as a function of depth range and open-water fraction threshold $1-\alpha$. The black contour shows the mean minimum sea ice cover for the period 2002-15.

minimum sea ice distribution. For $\alpha=0.65(35 \%$ open-water fraction), the floats have a chance to surface every $50-75$ days in the seasonal ice zone. This average is skewed toward the summer months, with likely higher chance to surface after each measurement during July-October, less so during freeze-up and melting seasons, and negligible chance during the winter months. Because sea ice cover has a clear seasonal cycle and mean seasonal minima, floats whose trajectories cross into the ice-free regions have high chances of surfacing every year. However, if a float drifts into the multiyear ice cover region just north of the Canadian

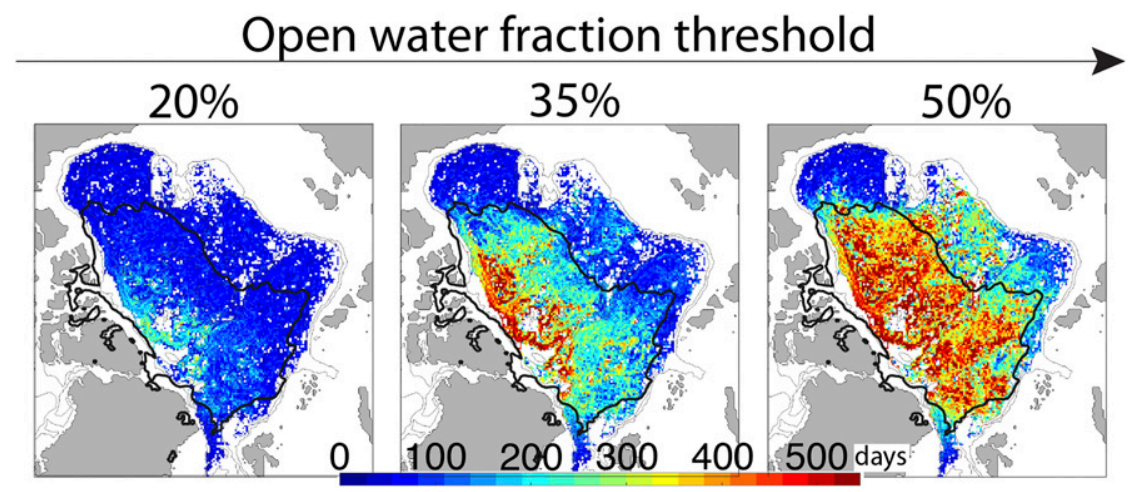

FIG. 13. Mean time interval (days) between consecutive resurfacing events, as a function of open-ocean threshold $1-\alpha$. Locations with low values can be considered "hot spots" where floats would surface frequently, and hydrographic measurements would be most useful. In regions such as north of the Canadian Archipelago, where values are high, the floats will likely remain silent for up to 2 years due to the presence of multiyear sea ice. 
Archipelago, it will likely remain noncommunicative during the majority of its lifetime. Future decrease in the summer sea ice minimum will increase the likelihood that the floats surface.

The trajectories of the $681 \times 200$ offline floats cover the entire Arctic Basin and yield between 5 and 30 hydrographic measurements per model grid cell for the computation of the three-dimensional field of $\bar{e}_{\Omega}$. Additional true floats (e.g., seeded at every grid point instead of every fourth) will likely improve the estimate of $\bar{e}_{\Omega}$, hot-spot maps and potential data yield, especially if seasonal maps are required. However, such a set of simulations would be significantly more expensive computationally. Given the spatial patterns of the time-mean estimated errors (Figs. 11 and 12), meaningful conclusions can already be drawn from our simulations, especially related to the distribution of multiyear versus seasonal sea ice (e.g., the patterns of errors and mean separation distance in relation to the 2002-15 sea ice minimum extent contour).

\section{c. Error quantification: Uncertainty revisited}

An ocean state estimate is deemed "representative" or "realistic" if the misfit between estimated and observed time-mean and time-dependent trajectories fall within the range $\sigma_{\Omega}$, which is the combined observation uncertainty and model representation error (Wunsch et al. 2009). Similarly, the "usefulness" of a float's measurements during its silent time is assessed based on whether the hydrographic misfits between true and sampled floats, $e_{\Omega}$, fall within $\sigma_{\Omega}$. Recall that in the error calculation, Eq. (5), $\sigma_{\Omega}$ enters as a normalization factor, raising the question to what extent the estimated value of $\sigma_{\Omega}$ affects the robustness of the results obtained here, in particular through its spatialscale dependence.

In this section, we briefly revisit how the uncertainty $\sigma_{\Omega}$ is obtained within the ECCO state estimation framework, and address the question whether it, and our usefulness assessment, are model-resolution dependent or a robust property of the real World Ocean.

In ECCO, $\sigma_{\Omega}^{2}$ (Fig. 5c) is calculated as the combination of observational data variability over a specified area (with the seasonal cycle removed; e.g., Forget and Wunsch 2007) and model representation error (Wunsch et al. 2009):

$$
\sigma_{\Omega}^{2}(L)=\left[\sigma_{\Omega}^{\mathrm{obs}}(L)\right]^{2}+\left[\sigma_{\Omega}^{\mathrm{rep}}(L)\right]^{2}
$$

where $L$ indicates the spatial length scale over which the mean and variance is calculated. Notice that spatial coverage of presently available observations in the ocean is sparse, and $\sigma_{\Omega}^{\mathrm{obs}}$ at the length scale $L$ can only be imperfectly approximated. The model representation error $\sigma_{\Omega}^{\text {rep }}$ is an estimate of how much the model horizontal grid scale cannot represent variability in the realWorld Ocean. For example, ASTE at the nominal grid spacing of $L \approx 15 \mathrm{~km}$, does not capture eddy activity at the first baroclinic radius of deformation. As a result, ASTE underestimates the true hydrographic variability, since it cannot represent subgrid-scale fluctuations, and a direct calculation of model-observation misfits would likely result in values comparable to the misrepresented subgrid-scale variability. To account for this, a representation error $\sigma_{\Omega}^{\text {rep }}$ is defined as the difference between the true variability of the ocean and that resulting from ASTE. Due to lack of sufficient spatiotemporal observational sampling, the ocean's "true" variability is not known, and is often inferred from output of very highresolution model simulations (Fig. 5b). Typically, at low model resolution, $\sigma_{\Omega}^{\text {rep }}$ is the dominating term in $\sigma_{\Omega}$.

The question arises whether our error estimate derived in section 2 would change substantially if a much higher horizontal resolution were used, for example, $L$ $\sim 500 \mathrm{~m}$, that can capture the first baroclinic mode in the Arctic. At this length scale, $\sigma_{\Omega}$ is estimated over a much smaller area of $0.5 \times 0.5 \mathrm{~km}^{2}$, where true ocean variability is expected to be higher than at larger spatial scales. Even though the model can now capture eddy activity, and will have near-zero $\sigma_{\Omega}^{\text {rep }}$, the term $\sigma_{\Omega}^{\text {obs }}$ is generally large, leaving the total $\sigma_{\Omega}$ relatively unchanged. This indicates that the coarse resolution of ASTE is not the deciding factor, since the uncertainty $\sigma_{\Omega}$ is largely independent of the particular length scale, and the approach to combine observational and representation error guards to some extent against a result being sensitive to horizontal model resolution.

Overall, in the absence of adequate observations of ocean velocity and hydrographic properties, their uncertainty fields are also an approximation, which can only be validated and improved with additional and appropriate measurements and noise models. Thus, a robust estimate of $\sigma_{\Omega}^{\text {rep }}$ remains very much a research question for the foreseeable future.

\section{Summary and outlook}

Relative to the recent drastic increase in Argo float coverage in most parts of the World Ocean interior, subsurface hydrographic observations in the Arctic Ocean have remained extremely sparse. In this study, we assess the utility of Argo-type floats in the Arctic and discuss the challenges associated with extended periods of no surfacing of such floats due the presence of sea ice. ASTE, a coupled ocean-sea ice state estimate constrained by satellite and in situ observations, was the 
primary computational tool used to conduct synthetic float numerical experiments. Furthermore, we developed metrics to quantify accumulated error in float positions and implied inferences of hydrographic measurement uncertainties while the floats probed under ice. We produced three-dimensional geographic maps of uncertainty in hydrographic measurements and twodimensional maps of float surfacing frequency.

Normalized mean errors in salinity (Fig. 11) were found to be below the uncertainty level across the entire Arctic Basin in the depth range 300-2000 m, rendering float measurements potentially useful despite errors due to unknown positions during silent time. Between 100 and $300 \mathrm{~m}$, the data can still be useful in some parts of the Arctic Basin, in regions outside the minimum summer sea ice cover (Fig. 11). In the upper ocean above $100 \mathrm{~m}$, the small spatial and temporal correlation length scale of ocean salinity yields normalized errors larger than the uncertainty in the majority of the Arctic Basin. Data are useful here only during the years of extreme sea ice minimum (e.g., top-left panel of Fig. 11).

Normalized mean errors in temperature (Fig. 12) are below the uncertainty level across the entire Arctic Basin through all depth ranges, with the only exception being the region below $300 \mathrm{~m}$ in the Eurasian Basin north of Fram Strait. This is a region of high variability, which leads to large estimated hydrographic errors (bottom-right panel of Fig. 12).

The geographic distribution of periods between surfacing events strongly correlates with the minimum Arctic sea ice cover (Fig. 13). If a float traverses the seasonal ice zone, its chance of surfacing is high, ranging from daily ( 1 day) to seasonal ( $<150$ days). If the float drifts into regions covered by multiyear sea ice, it can still likely surface during its 5-yr lifetime, with silent periods in the range of 200-450 days. Overall, Arctic Argo-type floats have a high chance to surface multiple times within their lifetime.

Normalized temperature and salinity errors $\bar{e}_{\theta}$ and $\bar{e}_{S}$ depend on the approximated flow field $\tilde{U}$, Eq. (2), which itself depends on the representation of the mean flow field $\mathbf{U}_{m}$ in ASTE, and on the uncertainty estimate $\boldsymbol{\sigma}_{\mathbf{U}}$. This flow field and the estimated errors can only be validated with additional hydrographic measurements. Improving upon present estimates will be an iterative process, but one in which formal state estimation and observing system design can play an important role: First, an ocean model constrained by available observations is used to help guide the initial float deployment by providing estimates of where floats will yield the most useful data. Next, floats are deployed, and their measurements are used to assess how accurate the initial error estimates are and establish where improvement is needed. These new measurements will then be incorporated into the state estimate to improve the model and update the "usefulness" estimates.

The error quantification results discussed here indicate that the current state of knowledge of the Arctic Ocean circulation and the model's ability to represent it will be improved with additional Argo-type Arctic float measurements (see Figs. 11 and 12), even in the presence of sea ice that inhibits the floats from relaying their position and measurements for potentially extensive periods of time that result in accumulated position and hydrographic errors. Given the spatial distribution of "hot spots" and expected hydrographic errors, forward and backward tracking can be employed to guide initial deployment locations to maximize the chance that the floats can surface and yield useful measurements during its expected 5-yr lifetime.

Adjoint sensitivity calculations, as shown in Nguyen et al. (2017), may provide added dynamic guidance to find the initial distribution of floats to best yield additional data in regions currently undersampled, for example, the eastern Arctic. Current and future Office of Naval Research and international efforts on the implementation of acoustic arrays in the Beaufort Sea and at Fram Strait, for example, Mikhalevsky et al. (2015), can further increase the data yield rate and measurement accuracy predicted from this modeling effort. The work presented here is a first step toward quantitative observing network design. Further efforts should be devoted to combining results obtained here with adjointbased methods to assess regions where new data would have high impact (Heimbach et al. 2011; Nguyen et al. 2017) and Hessian-based methods to support the design of optimal observing networks (Alexanderian et al. 2016; Kaminski et al. 2018; Loose 2019; Loose et al. 2020). To the extent that a path for moving Argo floats into the Arctic can be demonstrated, the Arctic Argo float program may become part of the global Argo portfolio and the global ocean observing system, thus drawing on the same resources and structures and closing an important gap in probing the depths of the world oceans.

Acknowledgments. This research was supported in part by NSF Office of Polar Program Grants 1603903 and 1643339.

\section{REFERENCES}

Adcroft, A., C. Hill, J.-M. Campin, J. Marshall, and P. Heimbach, 2004: Overview of the formulation and numerics of the MIT GCM. Proc. ECMWF Seminar on Recent Developments in Numerical Methods for Atmospheric and Ocean Modelling, Reading, United Kingdom, ECMWF, 139-150.

Alexanderian, A., N. Petra, G. Stadler, and O. Ghattas, 2016: A fast and scalable method for a-optimal design of experiments for 
infinite-dimensional Bayesian non-linear inverse problems. SIAM J. Sci. Comput., 38, A243-A272, https://doi.org/10.1137/ 140992564.

Beszczynska-Möller, A., E. Fahrbach, U. Schauer, and E. Hansen, 2012: Variability in Atlantic Water temperature and transport at the entrance to the Arctic Ocean, 1997-2010. ICES J. Mar. Sci., 69, 852-863, https://doi.org/10.1093/icesjms/fss056.

Buehner, M., P. Du, and J. Bedard, 2018: A new approach for estimating the observation impact in ensemble-variational data assimilation. Mon. Wea. Rev., 146, 447-465, https://doi.org/ 10.1175/MWR-D-17-0252.1.

Chamberlain, P. M., L. D. Talley, M. R. Mazloff, S. C. Riser, K. Speer, A. R. Gray, and A. Schwartzman, 2018: Observing the ice-covered Weddell Gyre with profiling floats: Position uncertainties and correlation statistics. J. Geophys. Res. Oceans, 123, 8383-8410, https://doi.org/10.1029/2017JC012990.

Cole, S. T., M.-L. Timmermanns, J. M. Toole, R. A. Krishfield, and F. T. Thwaites, 2014: Ekman veering, internal waves, and turbulence observed under Arctic sea ice. J. Phys. Oceanogr., 44, 1306-1328, https://doi.org/10.1175/JPO-D-12-0191.1.

Curry, B., C. Lee, B. Petrie, R. Moritz, and R. Kwok, 2014: Multiyear volume, liquid freshwater, and sea ice transports through Davis Strait, 2004-10. J. Phys. Oceanogr., 44, 1244-1266, https:// doi.org/10.1175/JPO-D-13-0177.1.

Dmitrenko, I. A., and Coauthors, 2010: Impact of the Arctic Ocean Atlantic Water layer on Siberian shelf hydrography. J. Geophys. Res., 115, C08010, https://doi.org/10.1029/2009JC006020.

Docquier, D., and Coauthors, 2019: Impact of model resolution on Arctic sea ice and North Atlantic Ocean heat transport. Climate Dyn., 53, 4989-5017, https://doi.org/10.1007/s00382019-04840-y.

Eastwood, S., K. R. Larsen, T. Lavergne, E. Nielsen, and R. Tonboe, 2011: Global sea ice concentration reprocessing product user manual. EUMETSAT Tech. Rep., 38 pp.

Fenty, I., and P. Heimbach, 2013: Coupled sea ice-ocean-state estimation in the Labrador Sea and Baffin Bay. J. Phys. Oceanogr., 43, 884-904, https://doi.org/10.1175/JPO-D-12-065.1.

_ D. Menemenlis, and H. Zhang, 2017: Global coupled sea ice-ocean state estimate. Climate Dyn., 49, 931-956, https:// doi.org/10.1007/s00382-015-2796-6.

Forget, G., and C. Wunsch, 2007: Estimated global hydrographic variability. J. Phys. Oceanogr., 37, 1997-2008, https://doi.org/ 10.1175/JPO3072.1.

—, J. Campin, P. Heimbach, C. N. Hill, R. M. Ponte, and C. Wunsch, 2015a: ECCO version 4: An integrated framework for non-linear inverse modeling and global ocean state estimation. Geosci. Model Dev., 8, 3071-3104, https://doi.org/ 10.5194/gmd-8-3071-2015.

— D. Ferreira, and X. Liang, 2015b: On the observability of turbulent transport rates by Argo: Supporting evidence from an inversion experiment. Ocean Sci., 11, 839-853, https:// doi.org/10.5194/os-11-839-2015.

Giering, R., and T. Kaminski, 1998: Recipes for adjoint code construction. ACM Trans. Math. Software, 24, 437-474, https:// doi.org/10.1145/293686.293695.

Gould, J., and Coauthors, 2004: Argo profiling floats bring new era of in situ ocean observations. Eos, Trans. Amer. Geophys. Union, 85, 185-191, https://doi.org/10.1029/2004EO190002.

Grist, J. P., S. A. Josey, A. L. New, M. Roberts, T. Koenigk, and D. Iovino, 2018: Increasing Atlantic ocean heat transport in the latest generation coupled ocean-atmosphere models: The role of air-sea interaction. J. Geophys. Res. Oceans, 123, 8624-8637, https://doi.org/10.1029/2018JC014387.
Heimbach, P., C. Hill, and R. Giering, 2005: An efficient exact adjoint of the parallel MIT general circulation model, generated via automatic differentiation. Future Gener. Comput. Syst., 21, 1356-1371, https://doi.org/10.1016/j.future.2004.11.010.

, C. Wunsch, R. M. Ponte, G. Forget, C. Hill, and J. Utke, 2011: Timescales and regions of the sensitivity of Atlantic meridional volume and heat transport: Toward observing system design. Deep-Sea Res. II, 58, 1858-1879, https://doi.org/10.1016/ j.dsr2.2010.10.065.

Hoffman, J. P., S. A. Ackerman, Y. Liu, and J. R. Key, 2019: The detection and characterization of Arctic sea ice leads with satellite imagers. Remote Sens., 11, 521, https://doi.org/10.3390/ RS11050521.

Holloway, G., and Coauthors, 2007: Water properties and circulation in arctic ocean models. J. Geophys. Res., 112, C04S03, https://doi.org/10.1029/2006JC003642.

Ilicak, M., and Coauthors, 2016: An assessment of the Arctic Ocean in a suite of interannual CORE-II simulations. Part III: Hydrography and fluxes. Ocean Modell., 100, 141-161, https:// doi.org/10.1016/j.ocemod.2016.02.004.

Ivanova, N., and Coauthors, 2015: Inter-comparison and evaluation of sea ice algorithms: Towards further identification of challenges and optimal approach using passive microwave observations. Cryosphere, 9, 1797-1817, https://doi.org/10.5194/ tc-9-1797-2015.

Kaminski, T., and Coauthors, 2018: Arctic mission benefit analysis: Impact of sea ice thickness, freeboard, and snow depth products on sea ice forecast performance. Cryosphere, 12, 2569-2594, https://doi.org/10.5194/tc-12-2569-2018.

Klatt, O., O. Boebel, and E. Fahrbach, 2007: A profiling float's sense of ice.J. Atmos. Oceanic Technol., 24, 1301-1308, https:// doi.org/10.1175/JTECH2026.1.

Kobayashi, S., and Coauthors, 2015: The JRA-55 reanalysis: General specifications and basic characteristics. J. Meteor. Soc. Japan, 93, 5-48, https://doi.org/10.2151/jmsj.2015-001.

Krishfield, R., J. Toole, A. Proshutinsky, and M.-L. Timmermans, 2008: Automated ice-tethered profilers for seawater observations under pack ice in all seasons. J. Atmos. Oceanic Technol., 25, 2091-2105, https://doi.org/10.1175/2008JTECHO587.1.

Kwok, R., 2018: Arctic sea ice thickness, volume, and multiyear ice coverage: Losses and coupled variability (1958-2018). Environ. Res. Lett., 13, 105005, https://doi.org/10.1088/ 1748-9326/AAE3EC.

—, and G. Cunningham, 2015: Variability of Arctic sea ice thickness and volume from CryoSat-2. Philos. Trans. Roy. Soc., 373A, 20140157, https://doi.org/10.1098/rsta.2014.0157.

__ _ _ - and S. S. Pang, 2004: Fram Strait sea ice outflow. J. Geophys. Res., 109, C01009, https://doi.org/10.1029/ 2003JC001785.

Lammers, R. B., and A. I. Shiklomanov, 2001: Assessment of contemporary Arctic river runoff based on observational discharge records. J. Geophys. Res., 106, 3321-3334, https:// doi.org/10.1029/2000JD900444.

Locarnini, R. A., and Coauthors, 2013: Temperature. Vol. 1, World Ocean Atlas 2013, NOAA Atlas NESDIS 73, 40 pp., http:// data.nodc.noaa.gov/woa/WOA13/DOC/woa13_vol1.pdf.

Loose, N., 2019: Adjoint modeling and observing system design in the subpolar North Atlantic. Ph.D. thesis, University of Bergen, 294 pp.

P. Heimbach, and H. Pillar, 2020: Quantifying dynamical proxy potential through oceanic teleconnections in the North Atlantic. J. Geophys. Res. Oceans, https://doi.org/10.1029/ 2020JC016112, in press. 
Marshall, J., A. Adcroft, C. Hill, L. Perelman, and C. Heisey, 1997: A finite-volume, incompressible Navier Stokes model for studies of the ocean on parallel computers. J. Geophys. Res., 102, 5753-5766, https://doi.org/10.1029/96JC02775.

Melia, N., K. Haines, and E. Hawkins, 2016: Sea ice decline and 21st century trans-Arctic shipping routes. Geophys. Res. Lett., 43, 9720-9728, https://doi.org/10.1002/2016GL069315.

Mikhalevsky, P., and Coauthors, 2015: Multipurpose acoustic networks in the integrated Arctic Ocean observing system. Arctic, 68, 11-27, https://doi.org/10.14430/arctic4449.

Murashkin, D., G. Spreen, M. Huntemann, and W. Dierking, 2018: Method for detection of leads from Sentinel-1 SAR images. Ann. Glaciol., 59, 124-136, https://doi.org/10.1017/aog.2018.6.

Nguyen, A. T., D. Menemenlis, and R. Kwok, 2011: Arctic ice-ocean simulation with optimized model parameters: Approach and assessment. J. Geophys. Res., 116, C04025, https://doi.org/ 10.1029/2010JC006573.

_ , V. Ocanã, V. Garg, P. Heimbach, J. Toole, R. Krishfield, C. Lee, and R. Rainville, 2017: On the benefit of current and future ALPS data for improving Arctic coupled ocean-sea ice state estimation. Oceanography, 30, 69-73, https://doi.org/ 10.5670/oceanog.2017.223.

Nurser, A., and S. Bacon, 2013: Eddy length scales and the Rossby radius in the Arctic Ocean. Ocean Sci. Discuss., 10, 1807-1831, https://doi.org/10.5194/osd-10-1807-2013.

Pnyushkov, A. V., I. V. Polyakov, V. V. Ivanov, and T. Kikuchi, 2013: Structure of the Fram Strait branch of the boundary current in the Eurasian Basin in the Arctic Ocean. Polar Sci., 7, 53-71, https://doi.org/10.1016/j.polar.2013.02.001.

,-- L. Padman, and A. T. Nguyen, 2018: Structure and dynamics of mesoscale eddies over the Laptev Sea continental slope in the Arctic Ocean. Ocean Sci., 14, 1329-1347, https:// doi.org/10.5194/os-14-1329-2018.

Polyakov, I. V., A. V. Pnyushkov, and L. A. Timokhov, 2012: Warming of the intermediate Atlantic Water of the Arctic Ocean in the 2000s. J. Climate, 25, 8362-8370, https://doi.org/ 10.1175/JCLI-D-12-00266.1.

— ice loss in the Eurasian Basin of the Arctic Ocean. Science, 356, 285-291, https://doi.org/10.1126/science.aai8204.

Proshutinsky, A., and Coauthors, 2009: Beaufort Gyre freshwater reservoir: State and variability from observations. J. Geophys. Res., 114, C00A10, https://doi.org/10.1029/2008JC005104.

Purokoski, T., E. Aro, and A. Nummelin, 2013: First long-term deployment of Argo float in Baltic Sea. Sea Technol., 54, 41-44.

Riser, S. C., and Coauthors, 2016: Fifteen years of ocean observations with the global Argo array. Nat. Climate Change, 6, 145-153, https://doi.org/10.1038/nclimate2872.

- D. Dwift, and R. Drucker, 2018: Profiling floats in SOCCOM: Technical capabilities for studying the Southern Ocean. J. Geophys. Res. Oceans, 123, 4055-4073, https://doi.org/ 10.1002/2017JC013419.

Roemmich, D., and Coauthors, 2009: The Argo program: Observing the global ocean with profiling floats. Oceangraphy, 22, 34-44, https://doi.org/10.5670/oceanog.2009.36.

— depth, multi-disciplinary array. Front. Mar. Sci., 6, 439, https:// doi.org/10.3389/fmars.2019.00439.

Rudels, B., 2012: Arctic Ocean circulation and variability-advection and external forcing encounter constraints and local processes. Ocean Sci., 8, 261-286, https://doi.org/10.5194/os-8-261-2012.

_- 2015: Arctic Ocean circulation, processes and water masses: A description of observations and ideas with focus on the period prior to the International Polar Year 2007-2009. Prog. Oceanogr., 132, 22-67, https://doi.org/10.1016/j.pocean.2013.11.006.

—, E. Jones, U. Schauer, and P. Eriksson, 2004: Atlantic sources of the arctic ocean surface and halocline waters. Polar Res., 23 , 181-208, https://doi.org/10.1111/j.1751-8369.2004.tb00007.x.

Schauer, U., and E. Fahrbach, 2004: Arctic warming through the Fram Strait: Oceanic heat transport from 3 years of measurements. J. Geophys. Res., 109, C06026, https://doi.org/ 10.1029/2003JC001823.

Serreze, M. C., and W. N. Meier, 2019: The Arctic's sea ice cover: Trends, variability, predictability, and comparisons to the Antarctic. Ann. N. Y. Acad. Sci., 1436, 36-53, https://doi.org/ 10.1111/nyas. 13856 .

Shiklomanov, A. I., T. I. Yakovleva, R. B. Lammers, I. P. Karasev, C. J. Vörösmarty, and E. Linder, 2006: Cold region river discharge uncertainty-Estimates from large Russian rivers. J. Hydrol., 326, 231-256, https://doi.org/ 10.1016/j.jhydrol.2005.10.037.

Tapley, B. D., and Coauthors, 2019: Contributions of GRACE to understanding climate change. Nat. Climate Change, 9, 358-369, https://doi.org/10.1038/s41558-019-0456-2.

Timmermans, M.-L., J. Toole, R. Krishfield, and P. Winsor, 2008: Ice-tethered profiler observations of the double-diffusive staircase in the Canada Basin thermocline. J. Geophys. Res., 113, C00A02, https://doi.org/10.1029/2008JC004829.

_ A. Proshutinsky, R. Krishfield, D. K. Perovich, J. A. RichterMenge, T. P. Stanton, and J. M. Toole, 2011: Surface freshening in the Arctic Ocean's Eurasian Basin: An apparent consequence of recent change in the wind-driven circulation. J. Geophys. Res., 116, C00D03, https://doi.org/10.1029/2011JC006975.

_ S. Cole, and J. Toole, 2012: Horizontal density structure and restratification of the Arctic Ocean surface layer. J. Phys. Oceanogr., 42, 659-668, https://doi.org/10.1175/JPO-D-11-0125.1.

_ J. Toole, and R. Krishfield, 2018: Warming of the interior Arctic Ocean linked to sea ice losses at the basin margins. Sci. $A d v .$, 4, eaat6773, https://doi.org/10.1126/sciadv.aat6773.

Toole, J. M., and Coauthors, 2006: Ice-tethered profilers sample the upper Arctic Ocean. Eos, Trans. Amer. Geophys. Union, 87, 434-438, https://doi.org/10.1029/2006EO410003.

—, M.-L. Timmermans, D. K. Perovich, R. A. Krishfield, A. Proshutinsky, and J. A. Richter-Menge, 2010: Influences of the ocean surface mixed layer and thermohaline stratification on Arctic sea ice in the central Canada Basin. J. Geophys. Res., 115, C10018, https://doi.org/10.1029/2009JC005660.

_ R. A. Krishfield, and M. L. Timmermans, 2011: The ice-tethered profiler: Argo of the Arctic. Oceanography, 24, 126-135, https:// doi.org/10.5670/oceanog.2011.64.

Torres, H. S., P. Klein, D. Menemenlis, B. Qiu, Z. Su, J. Wang, S. Chen, and L.-L. Fu, 2018: Partitioning ocean motions into balanced motions and internal gravity waves: A modeling study in anticipation of future space missions. J. Geophys. Res. Oceans, 123, 8084-8105, https://doi.org/ 10.1029/2018JC014438.

Wang, J., L.-L. Fu, B. Qiu, D. Menemenlis, J. T. Farrar, Y. Chao, A. F. Thompson, and M. M. Flexas, 2018: An observing system simulation experiment for the calibration and validation of the surface water ocean topography sea surface height measurement using in situ platforms. J. Atmos. Oceanic Technol., 35, 281-297, https://doi.org/10.1175/JTECH-D-17-0076.1.

Westerlund, A., and L. Tuomi, 2016: Vertical temperature dynamics in the northern Baltic Sea based on 3D modelling and data from shallow-water Argo floats. J. Mar. Syst., 158, 34-44, https://doi.org/10.1016/j.jmarsys.2016.01.006. 
Wong, A., and S. Riser, 2011: Profiling float observations of the upper ocean under sea ice off the Wilkes Land coast of Antarctica. J. Phys. Oceanogr., 41, 1102-1115, https://doi.org/ 10.1175/2011JPO4516.1.

_ and - 2013: Modified shelf water on the continental slope north of Mac Robertson Land, East Antarctica. Geophys. Res. Lett., 40, 6186-6190, https://doi.org/10.1002/2013GL058125.

Woodgate, R. A., 2018: Increases in the Pacific inflow to the Arctic from 1990 to 2015, and insights into seasonal trends and driving mechanisms from year-round Bering Strait mooring data. Prog. Oceanogr., 160, 124-154, https://doi.org/10.1016/ j.pocean.2017.12.007.

Wunsch, C., and P. Heimbach, 2007: Practical global oceanic state estimation. Physica D, 230, 197-208, https://doi.org/10.1016/ j.physd.2006.09.040.

_ , and —_, 2013a: Dynamically and kinematically consistent global ocean circulation and ice state estimates. Ocean Circulation and Climate: A 21st Century Perspective, Elsevier Ltd., 553-579, https://doi.org/10.1016/B978-0-12391851-2.00021-0 $\longrightarrow$, and — 2013b: Two decades of the Atlantic meridional overturning circulation: Anatomy, variations, extremes, prediction, and overcoming its limitations. J. Climate, 26, 7167-7186, https://doi.org/10.1175/JCLI-D-12-00478.1.

, — - R. Ponte, and I. Fukumori, 2009: The global general circulation of the Ocean estimated by the ECCOconsortium. Oceanography, 22, 88-103, https://doi.org/10.5670/ oceanog.2009.41.

Zhang, J., and D. Rothrock, 2003: Modeling global sea ice with a thickness and enthalpy distribution model in generalized curvilinear coordinates. Mon. Wea. Rev., 131, 845-861, https://doi.org/10.1175/1520-0493(2003)131<0845:MGSIWA > 2.0.CO;2.

Zhao, M., M.-L. Timmermans, S. Cole, R. Krishfield, and J. Toole, 2016: Evolution of the eddy field in the Arctic Ocean's Canada Basin, 2005-2015. Geophys. Res. Lett., 43, 8106-8114, https:// doi.org/10.1002/2016GL069671.

Zweng, M., and Coauthors, 2013: Salinity. Vol. 2, World Ocean Atlas 2013, NOAA Atlas NESDIS 74, 39 pp., http:// data.nodc.noaa.gov/woa/WOA13/DOC/woa13_vol2.pdf. 